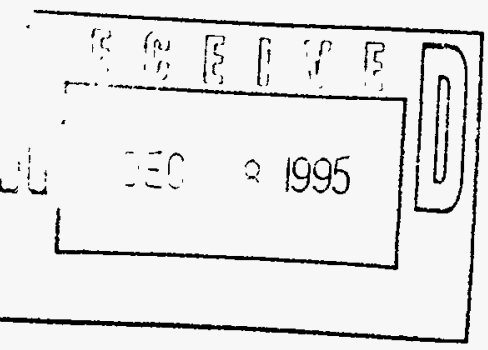

DOE/OR/00033--T699

\title{
CHARACTERIZATION OF A NUCLEAR ACCIDENT DOSIMETER
}

A Thesis

by

RONALD ALLEN BURROWS

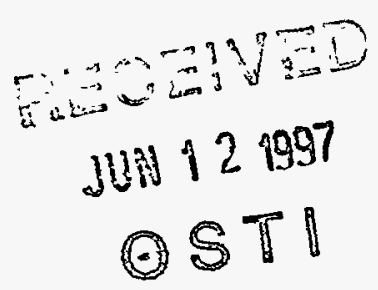

Submitted to the Office of Graduate Studies of

Texas A\&M University

in partial fulfillment of the requirements for the degree of

MASTER OF SCIENCE

December 1995

MASTER

Major Subject: Health Physics

DISTRIEUTION OF THIS DOCUMENT IS UNLIMITED 


\section{DISCLAIMIER}

Portions of this document may be illegible in electronic image produets. Images are produced from the best available original docoment. 


\title{
CHARACTERIZATION OF A NUCLEAR ACCDENT DOSIMETER
}

\author{
A Thesis
}

by

\section{RONALD ALLEN BURROWS}

\author{
Submitted to Texas A\&\& University \\ in partial fulfillment of the requirements \\ for the degree of \\ MASTER OF SCIENCE
}

Approved as to style and content by:
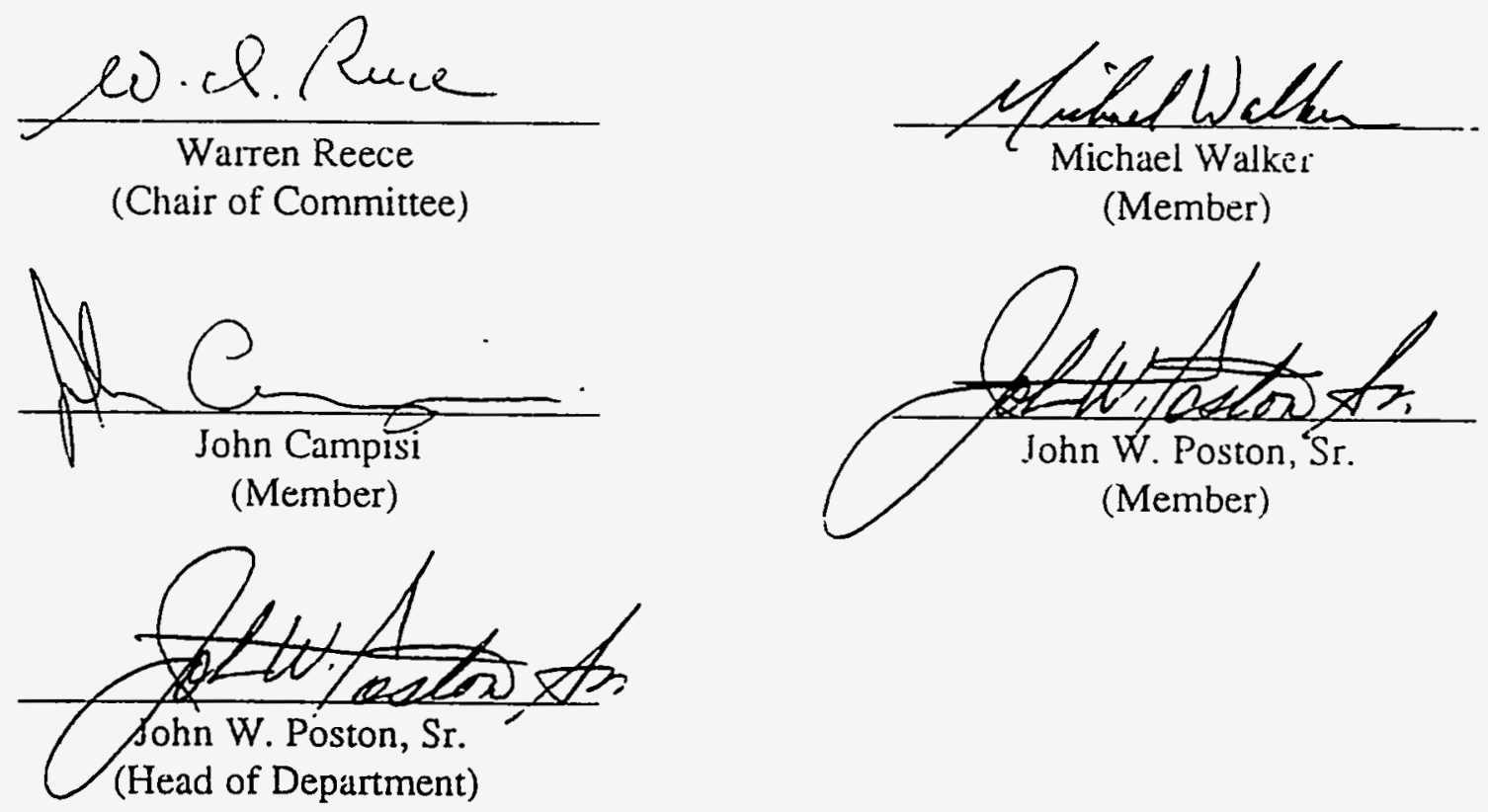

December 1995

Major Subject: Health Physics 


\author{
ABSTRACT \\ Characterization of a Nuclear Accident Dosimeter. (December 1995) \\ Ronald Allen Burrows, B.S., University of New Mexico; \\ M.B.A., New Hampshire College \\ Chair of Advisory Committee: Dr. Warren Reece
}

The 23rd nuclear accident dosimetry intercomparison was held during the week of June $12-16,1995$ at Los Alamos National Laboratory. This report presents the results of this event, referred to as NAD 23, as related to the performance of Sandia National Laboratories' (SNL) personal nuclear accident dosimeter (PNAD). Two separate critical assemblies, SHEBA and Godiva, were used to generate seven separate neutron spectra for use in dose comparisons. SNL's PNAD measured absorbed doses that were within +16 to +26 percent of the reference doses.

In addition, a preliminary investigation was undertaken to determine the feasibility of using the data obtained from an irradiated PNAD to correct for body orientation. This portion of the experiment was performed with a TRIGA reactor at the Nuclear Science Center at Texas A\&M University.

\title{
DISCLAIMER
}

This report was prepared as an account of work sponsored by an agency of the United States Government. Neither the United States Government nor any agency thereof, nor any of their employees, makes any warranty, express or implied, or assumes any legal liability or responsibility for the accuracy, completeness, or usefulness of any information, apparatus, product, or process disclosed, or represents that its use would not infringe privately owned rights. Reference herein to any specific commercial product, process, or service by trade name, trademark, manufacturer, or otherwise does not necessarily constitute or imply its endorsement, recommendation, or favoring by the United States Government or any agency thereof. The views and opinions of authors expressed herein do not necessarily state or reffect those of the United States Government or any agency thereof. 


\section{ACKNOWLEDGMENTS}

This research was performed under appointment to the Nuclear

Engineering/Health Physics Fellowship Program administered by Oak Ridge Institute for Science and Education for the U.S. Department of Energy.

In addition, Sandia National Laboratories and the Nuclear Science Center at Texas A\&M University have provided the resources and guidance necessary to carry out this research. 
TABLE OF CONTENTS

Page

ABSTRACT

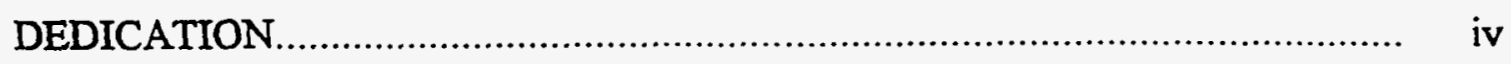

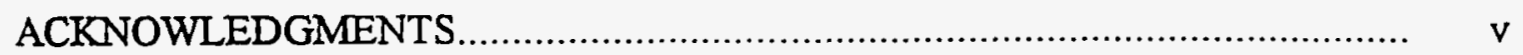

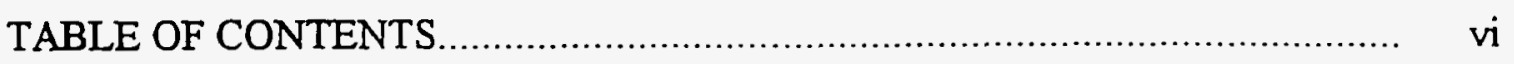

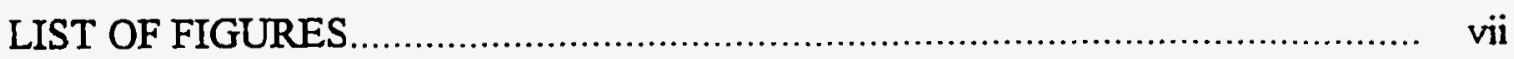

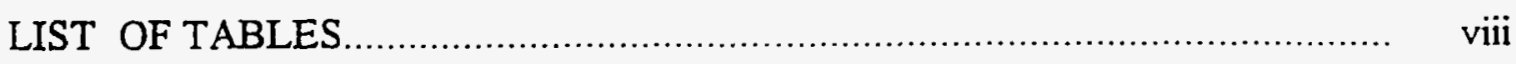

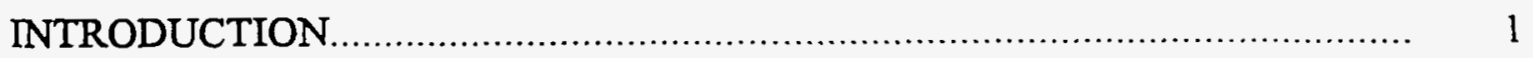

MATERIALS AND METHODS...............................................................

Neutron sources and reference dosimetry ................................................ 3

SNL dosimeters ............................................................................ 4

Determination of absorbed dose............................................................. $\quad 7$

Correction for body orientation................................................................. $\quad 8$

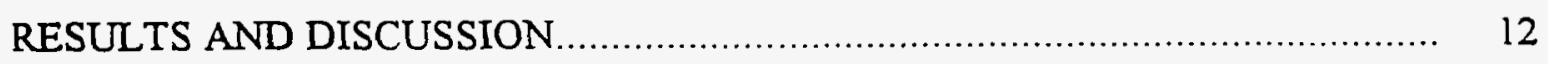

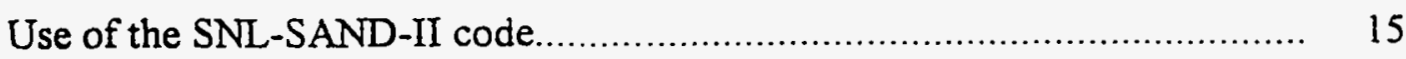

Dose calculation comparisons................................................................ 22

Activated sodium comparisons.................................................................. 24

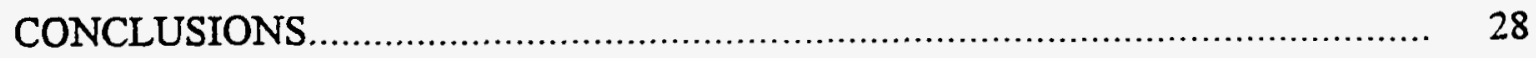

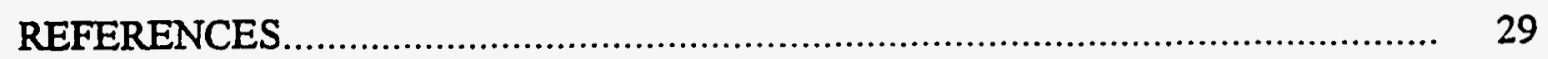

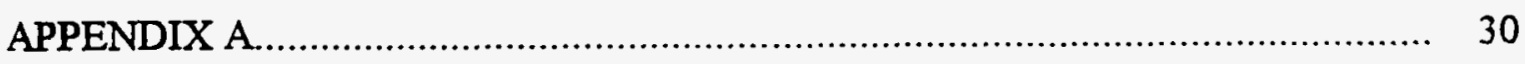

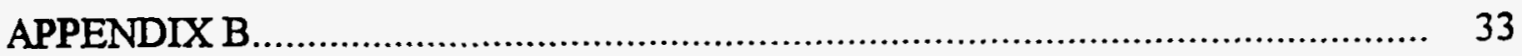

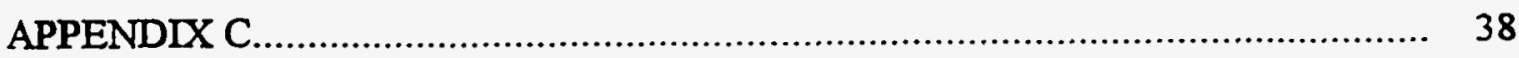

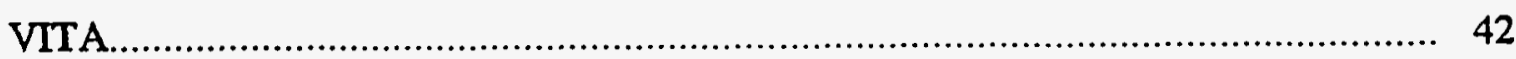




\section{LIST OF FIGURES}

FIGURE

Page

1

The SNL nuclear accident dosimeter.

5

2

Typical dosimeter mounting technique.

6

3

Phantom used for activated sodium comparison

10

4

Neutron dosimeter albedo effect

14

5

Results of irradiated foil measurements.

17

6

Comparison of the measured vs. calculated bare Godiva neutron spectrum.

Comparison of the SHEBA neutron spectrum with other neutron spectra.

Comparison of Godiva neutron spectra through shielding with other neutron spectra.

Dose calculation comparisons.

Activated sodium ratios.

Albedo effect on $\mathrm{NaF}$ tablets.

The Godiva critical assembly. 


\section{LIST OF TABLES}

\section{TABLE}

Page

1

Critical assembly configurations.......................................... 3

2

Activation foil characteristics

7

3

Comparison of measured dose to reference dose.

12

4

Comparison of charged particle dose to dose received by the $H(n, \lambda) D$ reaction.

13 


\section{INTRODUCTION}

Requirements for nuclear accident dosimetry are contained in 10 CFR 835 (DOE 1993). According to 10 CFR 835.1304 , installations possessing a sufficient quantity of fissile material to constitute a critical mass, such that the excessive exposure of personnel to radiation from a nuclear accident is possible, shall provide nuclear accident dosimetry for those personnel. While both fixed and personal nuclear accident dosimeters (PNADs) are required, this paper presents results only for the PNADs. A complete description of Sandia National Laboratories' (SNL) fixed nuclear accident dosimeter is given by Coats, et al. (1990).

Prior to NAD 23 there have been 25 nuclear accident dosimetry intercomparison studies, 22 of which were held at Oak Ridge National Laboratory using the Health Physics Research Reactor (HPRR). The last intercomparison study was held in 1985.

Representatives from nine facilities brought their accident dosimeters for testing. Each facility had a different design of dosimeter and a different method for determining the dose received from neutron exposure. In most cases, including SNL, there existed no documentation as to the results of previous intercomparisons. Therefore this intercomparison represented a much needed opportunity for individuals involved with dosimetry at these facilities, many of whom are new at their positions, to evaluate the performance of their accident dosimeters.

This thesis follows the format of the Journal of Health Physics. 
For SNL the primary objective of this research is to quantify the results of SNL PNADs relative to a known standard. The secondary objective is to provide written documentation on the PNAD performance including problems encountered during the study so that limitations of the PNAD can be taken into account during an actual accident.

My contribution to this project included sample preparation (PNAD disassembly, weighing of foils, recording of foil data), sample analysis using gamma spectroscopy, and recording analysis results for each criticality run. A portable high-purity germanium detector was used for sample analysis. A graded shield (copper inside of lead) was used to lower background radiation. The associated electronics were connected to a personal computer which contained the software for data analysis. Upon returning to SNL, I assisted in analyzing the results using the SNL-SAND-II and MCNP computer codes. I also generated various tables, graphs and figures for data presentation. In addition, I conceived of and carried out the method used for evaluating the $\mathrm{NaF}$ tablet used in the PNAD. I designed and constructed the phantom used for the sodium activation analysis and coordinated the reactor time required to perform this portion of the experiment. These samples were analyzed using gamma spectroscopy as well. 


\section{MATERIALS AND METHODS}

\section{Neutron sources and reference dosimetry}

Unlike most of the previous nuclear accident dosimeter intercomparison studies, the HPRR was not used as a source of neutrons. Instead, SHEBA (solution high energy burst assembly) and Godiva IV, two other critical assemblies at Los Alamos National Laboratory (LANL), were used. SHEBA is a right-circular cylindrically symmetrical assembly using a $5 \%$ enriched uranyl fluoride solution as fuel. The total dose delivered to a reference position at $3 \mathrm{~m}$ can be as high as $3-4$ Gray. Godiva IV is a bare metal fast burst assembly. The fuel is a 1.5 wt. $\% \mathrm{Mo}-\mathrm{U}\left(93.5 \%{ }^{235} \mathrm{U}\right)$ alloy. Unfiltered radiation dose at a reference position $3 \mathrm{~m}$ from the source can range from $0.1-5$ Gray. Appendix A contains a diagram of each assembly. In conjunction with Godiva IV, several of the original HPRR shielding components were used to modify the neutron spectrum. Table 1 lists the critical assembly configurations used in this experiment.

Table 1. Critical assembly configurations.

\begin{tabular}{ll}
\hline Assembly & Performance description \\
\hline SHEBA & - Low power \\
& - High power \\
& Free-run - Solution allowed to start and stop criticality on its \\
Godiva IV & own for several hours until a scram was initiated. \\
& - Sare \\
& - Spectrum modified through $20 \mathrm{~cm}$ concrete. \\
& - Spectrum modified through $12 \mathrm{~cm}$ lucite. \\
\hline
\end{tabular}


Reference dosimetry measurements were performed by LANL. The absorbed dose and dose equivalents were determined by a tissue equivalent proportional counter and the LANL Bonner sphere neutron spectrometer. The Bonner sphere system consists of 9 polyethylene spheres with a maximum diameter sphere of $30.5 \mathrm{~cm}(12 \mathrm{in})$. The detector is a $2.54-\mathrm{cm}\left(\mathrm{I}\right.$ in) diameter ${ }^{3} \mathrm{He}$ proportional counter. Appendix B lists the detailed spectra for the various criticality runs. These spectra were unfolded using a LANL developed computer program employing algorithms from the Spundit and SAND-II computer codes.

\section{SNL dosimeters}

The SNL PNAD is a compact unit that is worn in front of the body. The contents, shown in Fig. 1, include five metal activation foils and a sodium fluoride tablet. The foils are used primarily for determining absorbed dose and to a lesser extent provide a crude approximation of the neutron spectrum. The sodium fluoride tablet, when used in conjunction with activated blood sodium levels, can be used to help determine the orientation of the body and the PNAD when it was irradiated and thus a correction factor can be applied to the foil results. Unfortunately, this intercomparison was not set up to perform this type of analysis.

Before irradiating the PNADs they were mounted on a $40 \mathrm{~cm} \times 40 \mathrm{~cm} \times 15 \mathrm{~cm}$ lucite phantom as shown in Fig. 2. Phantoms were used to simulate the reflection of neutrons from the human body. PNADs were placed a minimum of $10 \mathrm{~cm}$ from any edge of the phantom to avoid the edge effect as discussed by Cummings et al. (1982). 


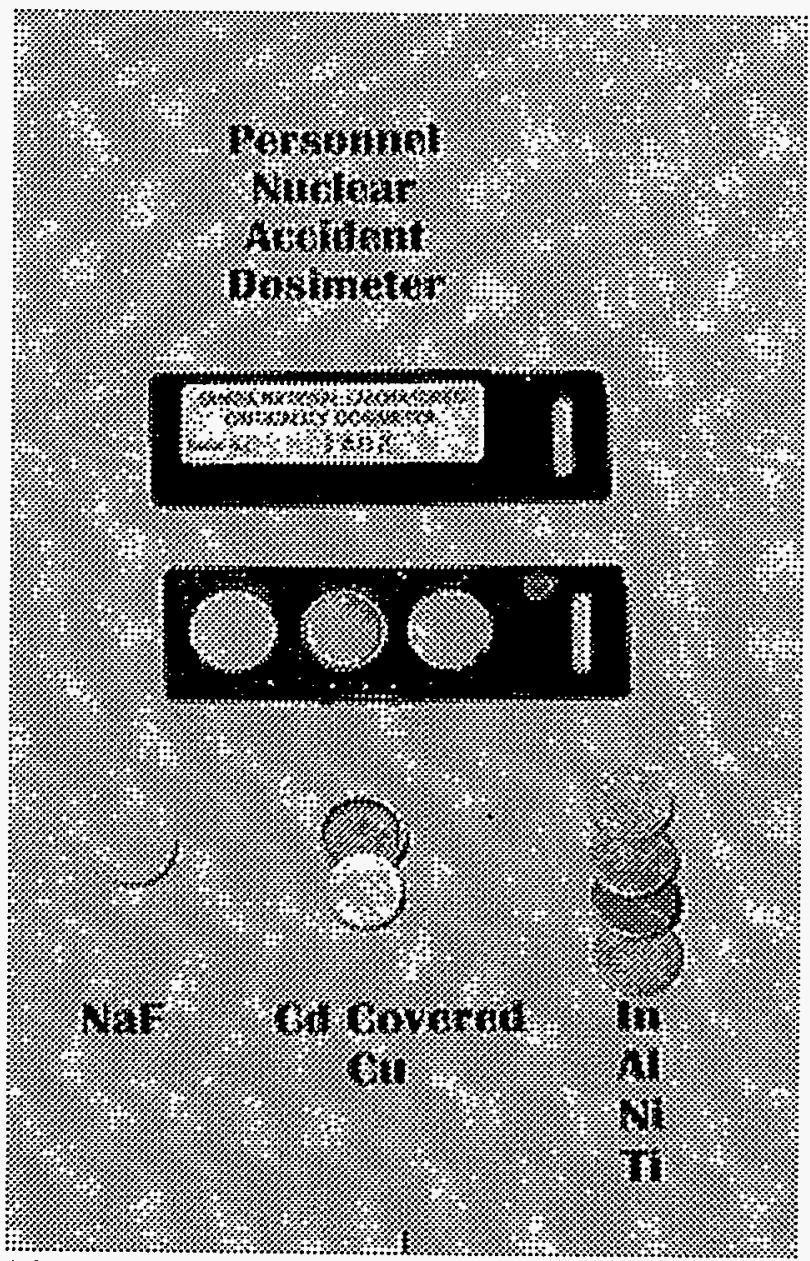

Fig. 1. The SNL nuclear accident dosimeter. 


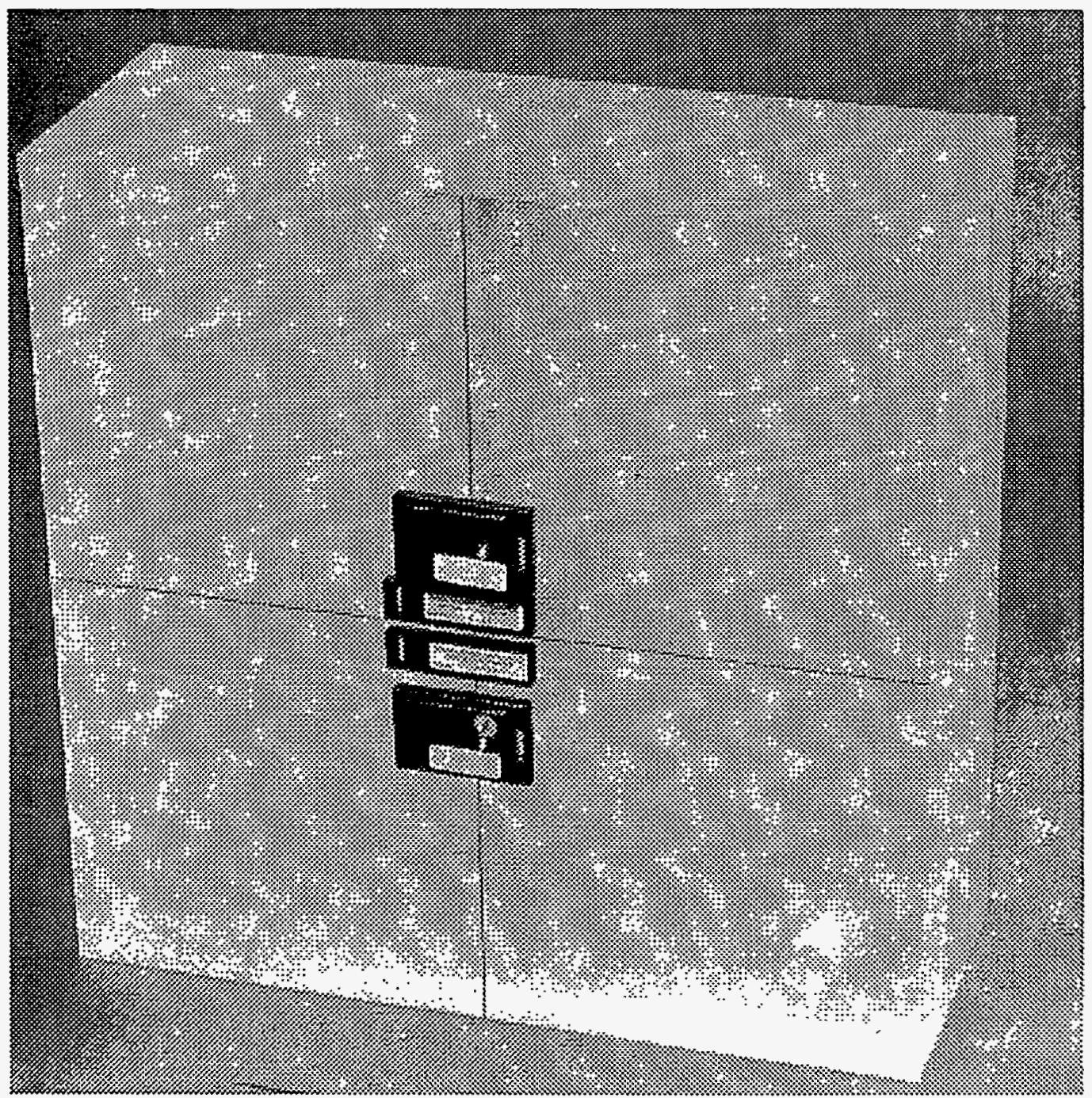

Fig. 2. Typical dosimeter mounting technique. 
Dosimeters mounted on the phantoms were placed $3 \mathrm{~m}$ from the centerline of the critical assembly, approximately $1.8 \mathrm{~m}$ above the ground.

To perform the sodium activation analysis, a $1,000 \mathrm{~kW}$ TRIGA reactor, located at the Nuclear Science Center at Texas A\&M University, was used to irradiate the PNADs.

\section{Determination of absorbed dose}

The activation foils will become radioactive after exposure to neutrons. This activity must then be related to the fluence and energies of the incident neutrons that exposed an individual. Table 2 lists the SNL foil characteristics used in determining the neutron fluence. A knowledge of the shape of the neutron spectrum is essential as a higher energy neutron will deliver a higher dose than a lower energy neutron. If a well documented spectrum is not available for a particular critical configuration then an estimate of the spectrum can be gained by using a reference such as Publication No. 180 by the International Atomic Energy Commission (IAEA 1978). This reference contains a listing of the spectrum of many critical assemblies and various shielding materials along with spectrum averaged cross sections for a few select foils and the associated dose conversion factors.

Table 2. Activation foil characteristics.

\begin{tabular}{cccccc}
\hline Foil & Reaction & $\mathrm{T}_{1 / 2}$ & $\begin{array}{c}\text { Gamma Yield } \\
(\%)\end{array}$ & $\begin{array}{c}\text { Gamma energy } \\
(\mathrm{MeV})\end{array}$ & $\begin{array}{c}\text { Effective } \\
\text { Threshold } \\
\text { Energy }(\mathrm{MeV})\end{array}$ \\
\hline $\mathrm{Cu}$ & ${ }^{63} \mathrm{Cu}(\mathrm{n}, \gamma){ }^{64} \mathrm{Cu}$ & $12.9 \mathrm{~h}$ & 0.49 & 1.346 & $\begin{array}{c}2 \mathrm{E}-06-1 \\
\text { (resonance) }\end{array}$ \\
$\mathrm{In}$ & ${ }^{115} \mathrm{In}\left(\mathrm{n}, \mathrm{n}^{\prime}\right){ }^{115 m} \mathrm{In}$ & $4.36 \mathrm{~h}$ & 45 & 0.336 & $1.2^{\mathrm{b}}$ \\
$\mathrm{Ni}$ & ${ }^{58} \mathrm{Ni}(\mathrm{n}, \mathrm{p}){ }^{58} \mathrm{Co}$ & $71.3 \mathrm{~d}$ & 99 & 0.81 & $3.8^{\mathrm{b}}$ \\
$\mathrm{Ti}$ & ${ }^{47} \mathrm{Ti}(\mathrm{n}, \mathrm{p}){ }^{47} \mathrm{Sc}$ & $3.4 \mathrm{~d}$ & 68 & 0.16 & $2.6^{\mathrm{b}}$ \\
$\mathrm{Al}$ & ${ }^{27} \mathrm{Al}(\mathrm{n}, \alpha){ }^{24} \mathrm{Na}$ & $15 \mathrm{~h}$ & 100 & 1.369 & $8.2^{\mathrm{b}}$ \\
\hline
\end{tabular}

Griffin, et. al. 1993

${ }^{b}$ IAEA 1982. Effective threshold is defined here as that energy at which the cross section reaches $50 \%$ of its maximum. 
The fluence is calculated with the following formula:

$$
\Phi\left(n / \mathrm{cm}^{2}\right)=\frac{\text { FoilActivity }(\mu \mathrm{Ci} / \mathrm{g})}{\operatorname{NoY\lambda PS}(2.7 E-05 \mu C i / \text { d.p.s. })}
$$

Where:

$\mathrm{N}=$ number of atoms per gram of foil weight

$\mathrm{Y}=$ fractional abundance of isotope

$\lambda=$ decay constant

$\sigma=$ spectrum averaged cross section

$\mathrm{P}=$ fractional elemental purity

$\mathrm{S}=$ self absorption correction

It is suggested (IAEA 1978) to use the foil resulting in the lowest counting error to determine the fluence. In all cases the indium foil satisfied this criteria. The other foils were then used to check the results. If there is good agreement between all foil types then one can have a high degree of confidence in the value of the dose estimate. However, body position still needs to be considered.

\section{Correction for body orientation}

The sodium fluoride tablets, as with the other foils, will become activated to various extents dependent upon body orientation with respect to the neutron flux. The three body orientations examined were the frontal, or anterior-posterior (AP) exposure, the rear, or posterior-anterior (PA) exposure, and the side, or lateral (LAT) exposure.

It is desirable to be able to determine if an exposed individual was in a position other than the AP orientation as is often assumed during the testing of criticality dosimeters. As a 
source of comparison, a blood sample would be drawn from an exposed individual and the sodium activity in the blood would be compared to that of the sodium fluoride tablets. It is the intention of this part of the experiment to ascertain if it is possible, based on a comparison of these activated sodium levels, to determine body orientation.

To conduct this portion of the experiment a phantom similar to that shown in Fig. 2 was designed and constructed out of paraffin. Three wells were designed into this phantom so that three one-liter polyethylene bottles, each filled with a sodium solution, could be placed into the phantom for irradiation. This is shown in Fig. 3. Three liters of solution was chosen as a reference volume based on a study (Leggett and Williams 1991) indicating three liters of blood reside in the upper trunk portion of the human body.

A solution to represent human blood was made with sodium hydroxide. The reference man value for blood sodium content is approximately $1.92 \mathrm{mg} \mathrm{Na} / \mathrm{ml}$ blood (ICRP 1974). However, due to the duration of this portion of the experiment a modification to this value was made. Based on anticipated contact readings of the solution and the amount of decay time required to enable the detector system to count the samples, it was decided to reduce the concentration of the solution to $1.92 \mathrm{mg} \mathrm{Na} / \mathrm{L}$ of solution. This still enables a study of relative ratios between the tablets and solution. After the preliminary study, a more detailed study can be conducted to determine more realistic ratios.

Two configurations were tested with the TRIGA reactor. The first test was with two sheets (approximately 0.5 in. total) of boral (a material containing boron carbide) 


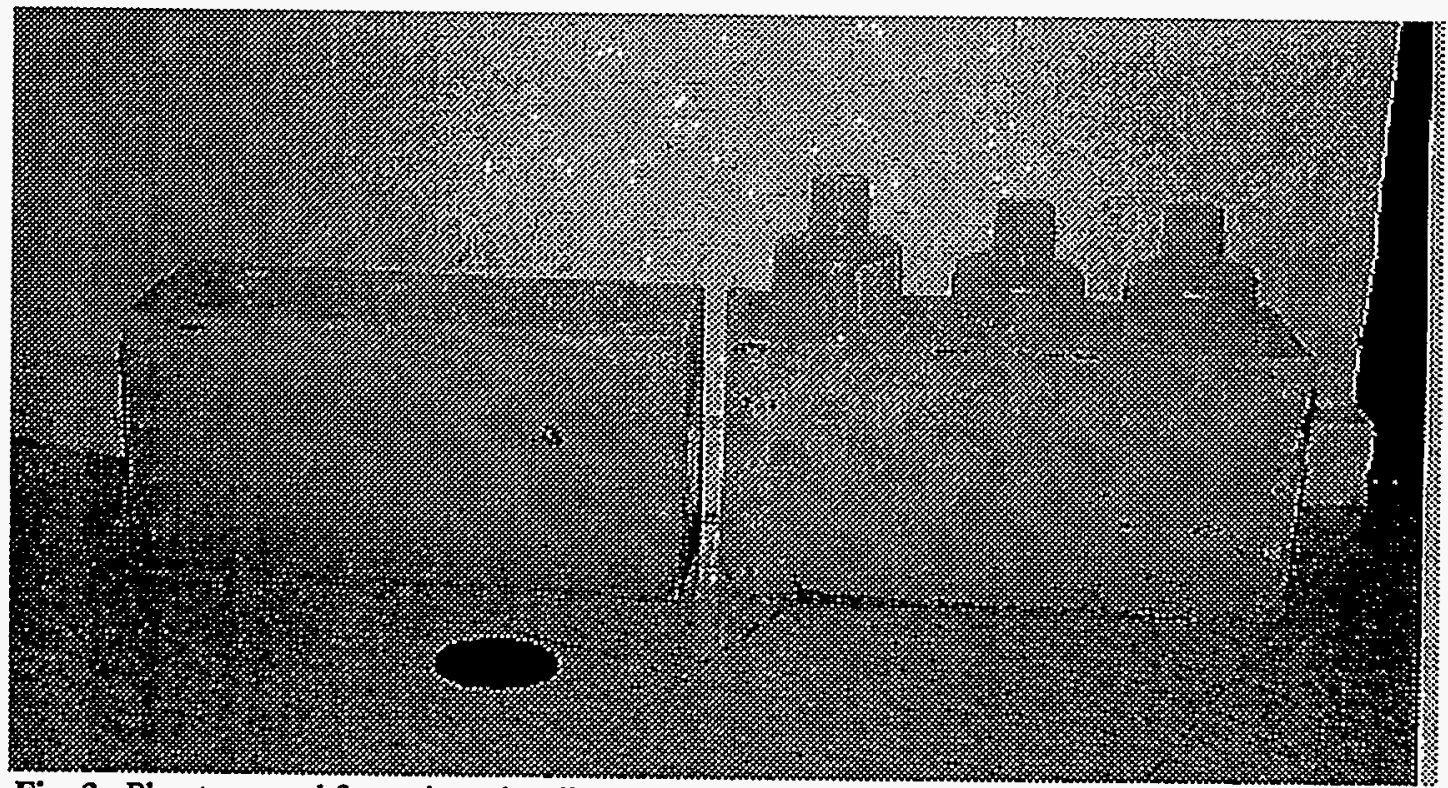

Fig. 3. Phantom used for activated sodium comparison. 
placed between the reactor and the phantom to absorb thermal neutrons. These neutrons tend to activate the sodium to a great extent without contributing significantly to absorbed dose. The reactor was operated for twenty minutes at $10 \mathrm{~kW}$ and then a scram was initiated. A second test was then performed without the boral in place. The exposure was at $10 \mathrm{~kW}$ for ten minutes before a scram was initiated.

The sodium solution was allowed to decay and then counted in a Marinelli beaker capable of holding all three liters of solution. Clean polyethylene bottles and fresh sodium hydroxide solution were replaced for each irradiation. 


\section{RESULTS AND DISCUSSION}

Table 3 lists the results of the indium foil only. Dose estimates ranged from +16 to +26 percent of the reference dose.

Table 3. Comparison of measured dose to reference dose.

\begin{tabular}{lccc}
\hline \multicolumn{1}{c}{ Spectrum $^{2 b}$} & $\begin{array}{c}\text { Reference dose }^{\mathrm{a}} \\
\text { (Grav) }\end{array}$ & $\begin{array}{c}\text { Measured dose } \\
\text { (Gray) }\end{array}$ & $\begin{array}{c}\text { Measured/reference } \\
(\%)\end{array}$ \\
\hline SHEBA high power & 1.08 & 1.25 & 16 \\
SHEBA low power & 0.11 & 0.13 & 18 \\
SHEBA free-run & 0.94 & 1.14 & 21 \\
Bare Godiva & 2.00 & 2.51 & 26 \\
Godiva through $12 \mathrm{~cm}$ & 0.26 & 0.31 & 19 \\
$\begin{array}{l}\text { lucite } \\
\text { Godiva through } 20 \mathrm{~cm}\end{array}$ & 0.34 & 0.41 & 22 \\
concrete & & & \\
\hline
\end{tabular}

- As measured by Los Alamos National Laboratory at $3 \mathrm{~m}$ from source.

${ }^{6}$ Data for Godiva through steel not available from LANL at this date.

' Charged particle dose based on In foil which had lowest counting enror in all cases. Dosimeters placed $3 \mathrm{~m}$ from source on lucite phantom. Dose conversion factors used were calculated with the SNL-SANDII code.

d Some values do not match due to rounding.

As mentioned previously, a knowledge of the neutron spectrum is necessary in order to determine the dose received by an individual. Below neutron energies of $10 \mathrm{keV}$ the dose is principally due to the $H(n, \gamma) D$ reaction. Above $10 \mathrm{keV}$, the dose results mainly from recoil protons from the elastic scattering of hydrogen nuclei (Attix 1986). This effect can be seen from Table 4 . There is a noticeable increase in the dose contribution from the $\mathrm{H}(\mathrm{n}, \gamma) \mathrm{D}$ reaction as the amount of moderation is increased. These doses were calculated using the LANL supplied spectra as input into the SNL-SAND-II 
code. Doses reported for criticality accidents are typically stated in terms of charged particle dose as are the reference and measured doses reported in this paper.

Table 4. Comparison of charged particle dose to dose received by the H(n. $\gamma)$ D reaction.

\begin{tabular}{lccc}
\hline \multicolumn{1}{c}{ Spectrum } & $\begin{array}{c}\mathrm{D}_{\mathrm{ep}} \text {, charged particle } \\
\text { dose to El-57 (Gray) }\end{array}$ & $\begin{array}{c}\text { D } \gamma, \text { gamma dose from } \\
\text { H(n, } \gamma) \mathrm{D}(\mathrm{Gray})^{\mathrm{c}}\end{array}$ & $\begin{array}{c}\mathrm{D} \gamma / \mathrm{D}_{\text {tod }}{ }^{\mathrm{d}} \\
(\%)\end{array}$ \\
\hline SHEBA high power & 1.25 & 0.16 & 11 \\
SHEBA low power & 0.13 & 0.02 & 13 \\
SHEBA free-run & 1.14 & 0.15 & 11 \\
Bare Godiva & 2.51 & 0.31 & 11 \\
$\begin{array}{l}\text { Godiva through } 12 \mathrm{~cm} \\
\text { lucite }\end{array}$ & 0.31 & 0.05 & 14 \\
$\begin{array}{l}\text { Godiva through } 20 \mathrm{~cm} \\
\text { concrete }\end{array}$ & 0.44 & 0.10 & 19 \\
\hline
\end{tabular}

As measured by Los Alamos National Laboratory at $3 \mathrm{~m}$ from source.

${ }^{b}$ Data for Godiva through steel not available from LANL at this date.

${ }^{\circ}$ Based on In foil results.

${ }^{d} D_{\text {Lot }}-D_{\text {cp }}+D_{\gamma}$

Unlike neutron thermoluminescent dosimeters, the PNADs do not rely on the ability of the body to reflect incident neutrons. The body will however moderate and reflect the incident neutron spectrum. Therefore it can be expected that the PNADs will overrespond due to this albedo effect. To try and determine how much the PNADs overrespond, PNADs were also placed away from reflecting surfaces so that an "in-air" reading could be obtained. The results for several spectra are shown in Fig. 4. These results indicate that for nuclear accident purposes the reported dose is only slightly conservative $(+16$ to +26 percent of the reference dose) when compared to in-air dosimeter readings ( -25 to $+19 \%$ of the reference dose). This level of 


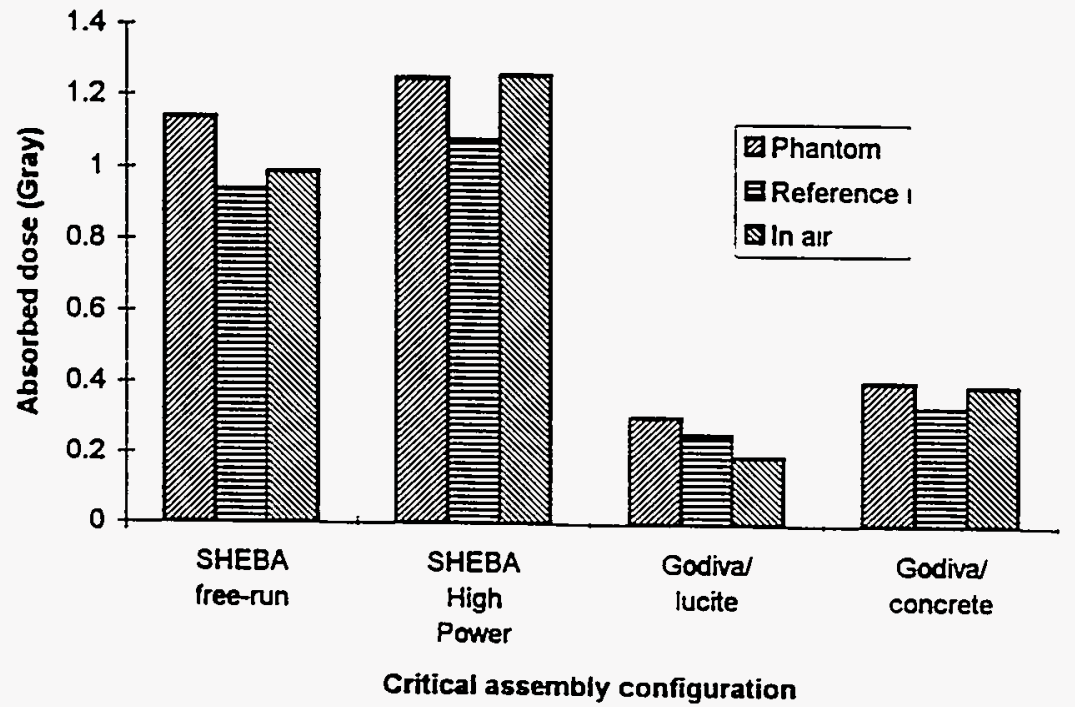

Fig. 4. Neutron dosimeter albedo effect. 
conservatism would not change the diagnosis of the exposed individual.

\section{Use of the SNL-SAND-II code}

The SNL-SAND-II neutron spectrum unfolding code, a modified version of the

SAND-II code, is typically used to determine the shape of a neutron spectrum by using as its input the activities of numerous activation foils. It can also be used for another useful purpose as well. Using as input the detailed spectrum information from LANL (see Appendix B), SNL-SAND-II was used to calculate the spectrum averaged cross sections and the dose conversion factors. A detailed description of the SAND-II code is given by McElroy et al. (1967). The advantage in doing this is that these values should represent a more realistic picture of the neutron spectrum. compared to published values, by taking the physical environment of the critical assembly into account (e.g., scattering of neutrons from structural materials back to the dosimeters). Using this method also allows the user to obtain information on any material available in the dosimetry library that the code accesses. Griffin et al. (1993) describe the dosimetry libraries that SAND-II uses for each reaction of interest. SNL-SAND-II computed values are shown in Table 5. 
Table 5. Spectrum averaged cross sections and dose conversion factors ${ }^{2 \mathrm{~b}}$.

\begin{tabular}{|c|c|c|c|c|}
\hline \multicolumn{5}{|c|}{ Spectrum } \\
\hline & SHEBA & $\begin{array}{l}\text { Bare } \\
\text { Godiva }\end{array}$ & $\begin{array}{l}\text { Godiva } \\
\text { through } 12 \\
\text { cm lucite }\end{array}$ & $\begin{array}{l}\text { Godiva } \\
\text { through } 20 \mathrm{~cm} \\
\text { concrete }\end{array}$ \\
\hline & \multicolumn{4}{|c|}{ Spectrum averaged cross sections (barns) } \\
\hline $\mathrm{Cu}$ & 0.0662 & 0.1014 & 0.1432 & 0.1720 \\
\hline In & 0.0933 & 0.1009 & 0.0728 & 0.0437 \\
\hline $\mathrm{Ni}$ & 0.0680 & 0.0607 & 0.0364 & 0.0208 \\
\hline $\mathrm{Ti}$ & 0.0116 & 0.0103 & 0.0064 & 0.0037 \\
\hline \multirow[t]{2}{*}{ Al } & 0.0017 & 0.0007 & 0.0003 & 0.0003 \\
\hline & \multicolumn{4}{|c|}{ Dose conversion factors (nGrav/n/ $\mathrm{cm}^{2}$ ) } \\
\hline$D_{\mathrm{ep}}^{c}$ & $2.03 \mathrm{E}-02$ & $2.06 E-02$ & $1.40 \mathrm{E}-02$ & $1.08 \mathrm{E}-02$ \\
\hline$D \gamma^{d}$ & $2.60 \mathrm{E}-03$ & $2.50 E-03$ & $2.30 \mathrm{E}-03$ & $2.50 E-03$ \\
\hline
\end{tabular}

\footnotetext{
'Spectral data supplied by Los Alamos National Laboratory, values calculated with SNL-SAND-II code.

${ }^{b}$ Data for Godiva through steel not available from LANL at this date.

${ }^{\circ}$ Charged particle dose to El-57.

${ }^{\mathrm{d}}$ Gamma dose from $\mathrm{H}(\mathrm{n}, \gamma) \mathrm{D}$.
}

Using the SNL-SAND-II values, the neutron doses were recalculated using all foil results. Fig. 5 shows the results of the dose calculations for the various spectra. Errors shown in this figure are those associated with the counting system only. A couple of important observations can be made from this figure. First, all foils were not activated in all cases. In those cases where the other foils were activated, the $\mathrm{Ni}$, $\mathrm{Ti}$, and $\mathrm{Al}$ foils required a minimum of a 1 hour count time to achieve the same counting statistics as a ten minute In foil count. Second, the copper foil consistently resulted in a dose estimate that was 4 to 10 times higher than the reference dose when the values from the SNL-SAND-II code were used for the specific LANL measured spectra. This is an improvement to using the theoretical spectrum values for copper (e.g., the bare Godiva spectrum as calculated by Ing in IAEA 1978) which resulted in dose estimates that were 8 to 12 times higher than 

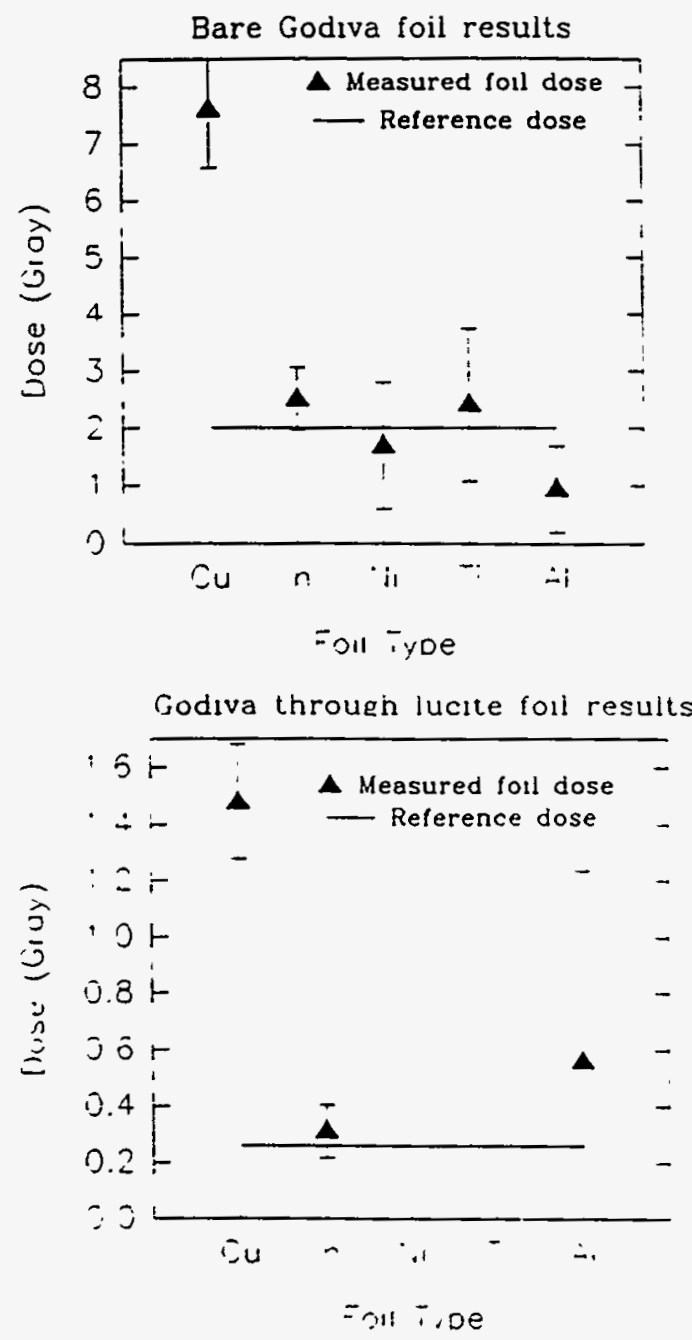

Godiva through concrete 1011 results

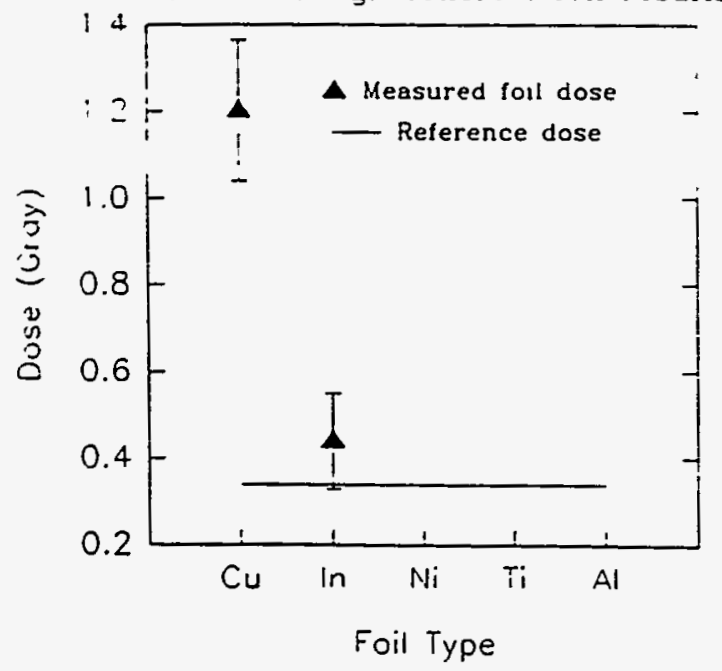

Fig. 5. Results of irradiated

SHEBA high power foll results
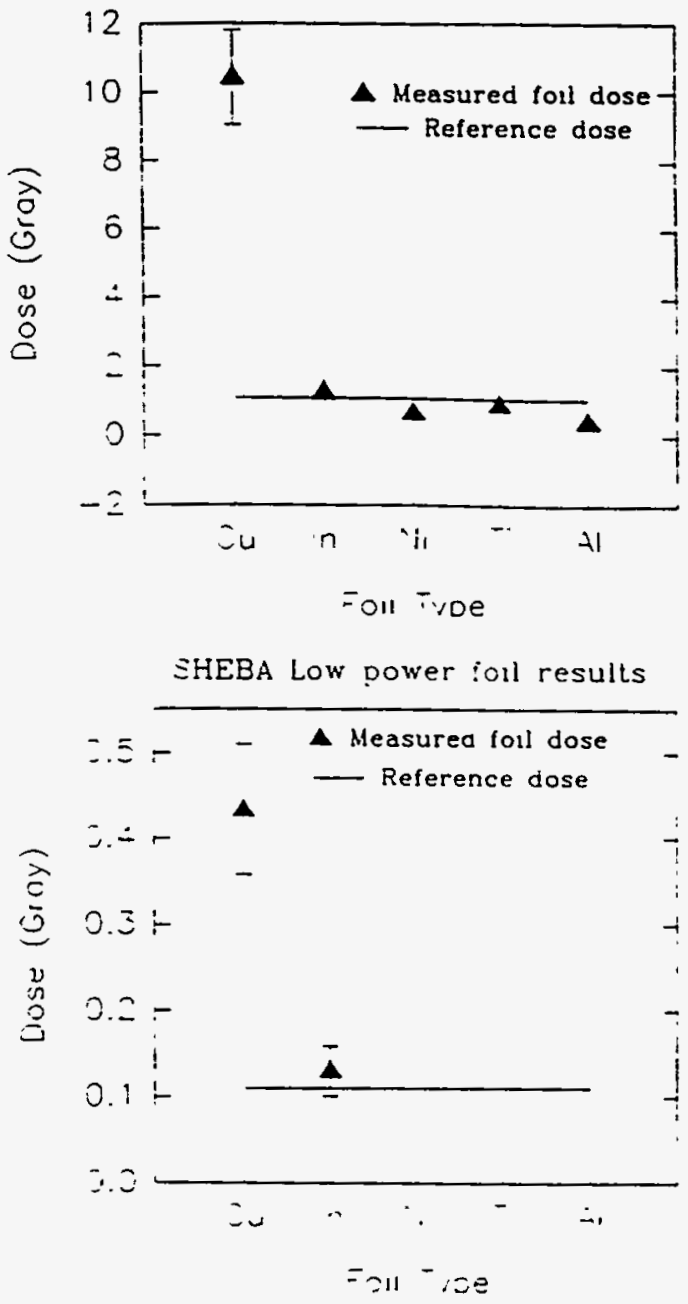

SHEBA iree-run foll results

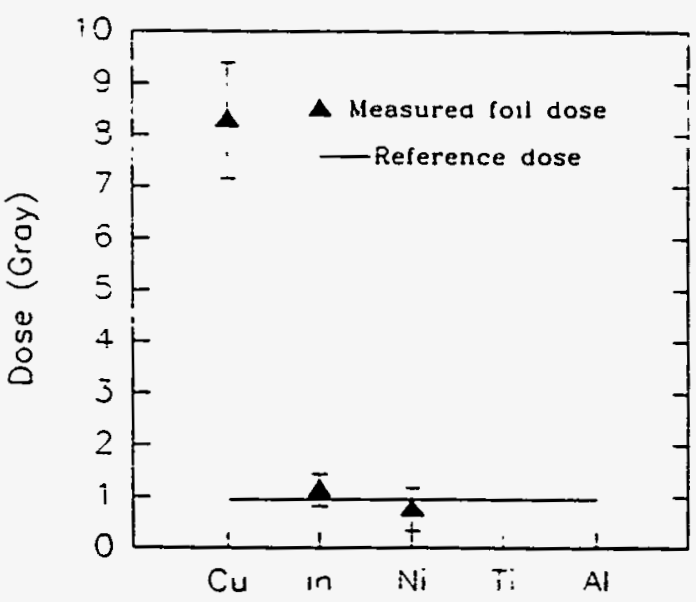

Foil Type

foil measurements. 


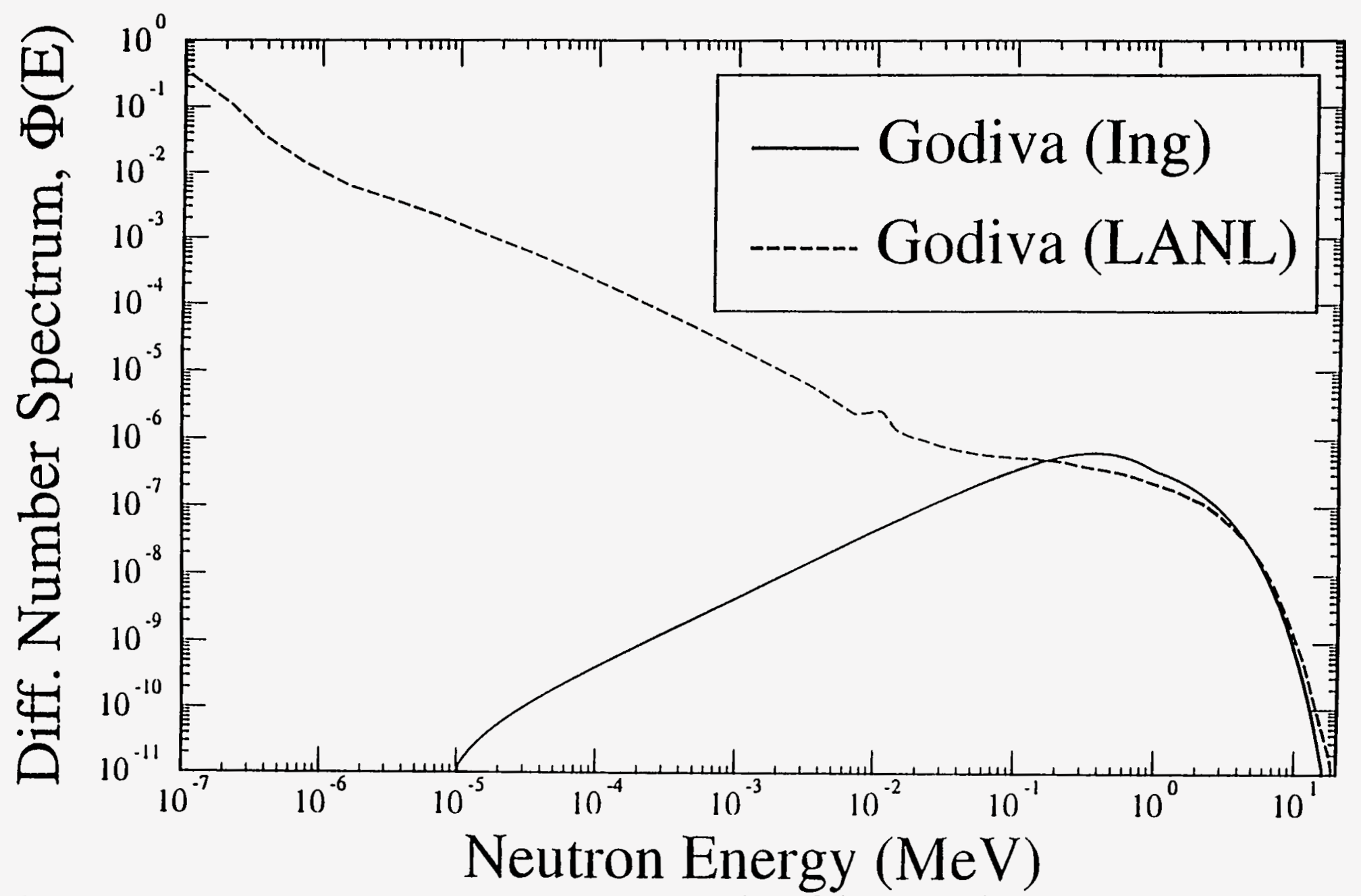

Fig. 6. Comparison of the measured vs. calculated bare Godiva neutron spectrum. 
the reference dose. One reason for this is clear when the actual spectrum is examined. Fig. 6 compares the LANL measured bare Godiva spectrum with the calculated spectrum from the same assembly. The LANL measured spectrum includes backscattered neutrons from the concrete enclosure that the Godiva assembly was housed in. As the resonance region of copper lies in the $2.0 \mathrm{E}-06$ to $1 \mathrm{MeV}$ energy range, the cross section for this spectrum will be much higher compared to one that does not include the backscatter. The cadmium cover on the copper foil will attenuate the thermal neutrons before reaching the copper foil but will not affect the intermediate and fast energy neutrons. Indium, as well as the other bare foils, are not affected by this as their threshold energy is $1 \mathrm{MeV}$ and higher.

Several questions were then raised to try and solve the problem with the copper foil. Copper is easily activated and thus it could be useful in determining dose. The first question to be answered is how well the LANL spectra (SHEBA and Godiva) themselves are characterized. If neutrons that have energies in the copper resonance region are underrepresented then there will be an increase in the estimate of the dose when using a spectrum weighted cross section for copper. There is some indication of this as shown in Fig. 7. Also of interest is the endpoint energy of the SHEBA spectrum. It is not physically possible for the endpoint to extend past the Watt spectrum. The spectra for the shielded Godiva configurations are shown in Fig. 8. The spectra marked LANL are those measured at by LANL for use in this comparison.

The second question was whether any downscatter of neutrons was occurring in the 30 mil cadmium cover that the copper foil was encased in. The SNL-SAND-II code 


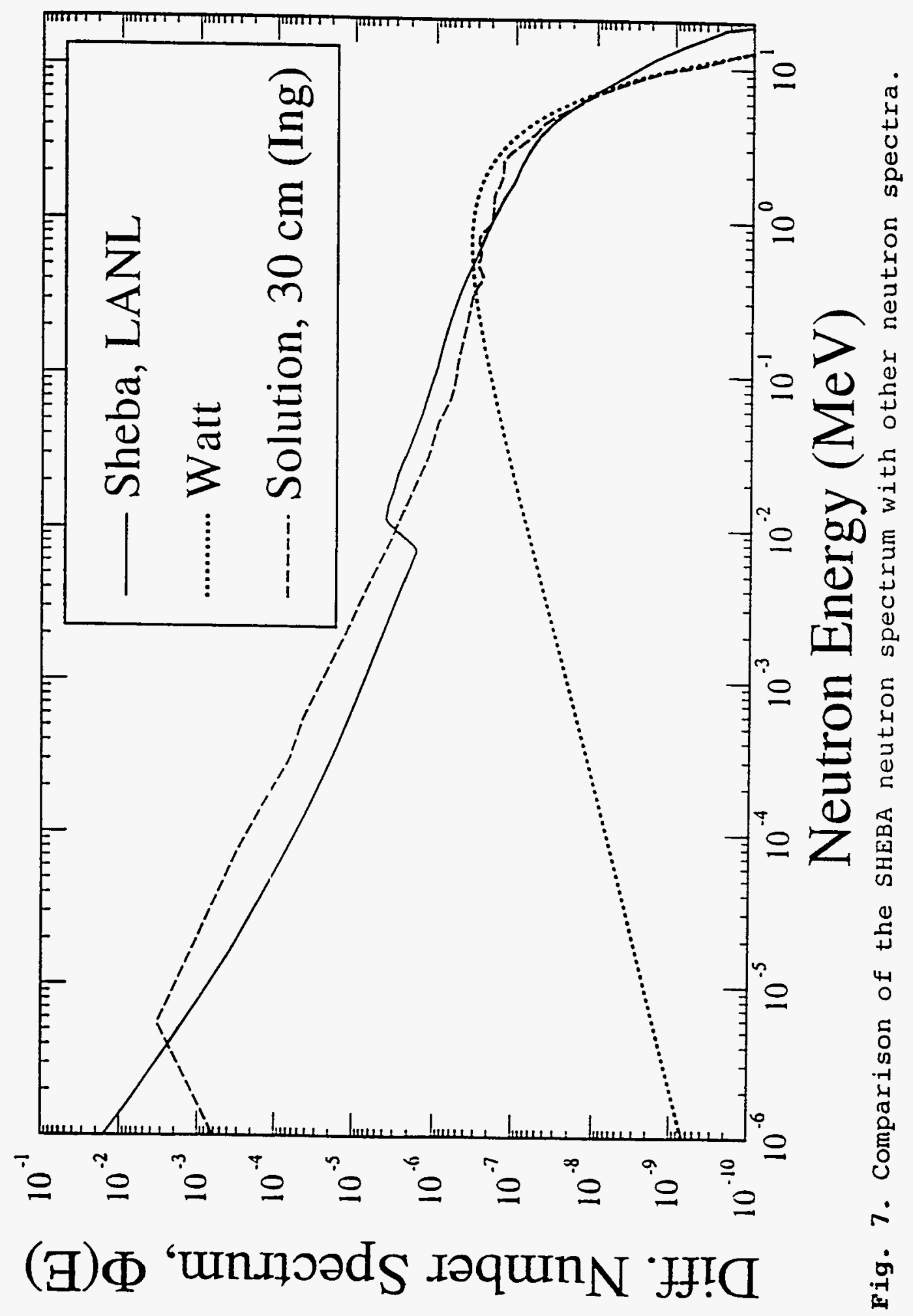




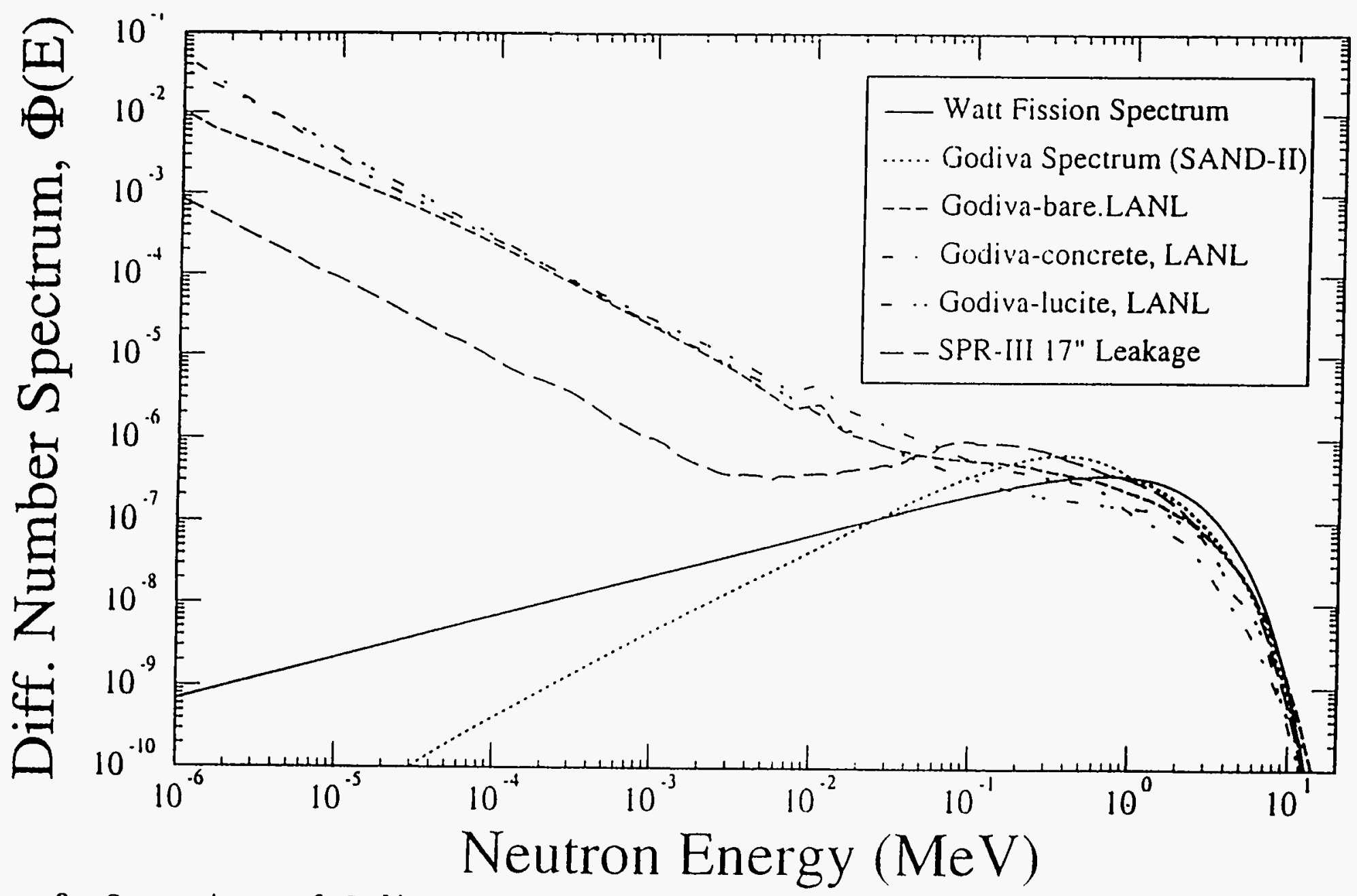

Fig. 8. Comparison of Godiva neutron spectra through shielding with other neutron spectra. 
does not take downscattering into consideration. For cadmium covers it applies an exponential attenuation in the cadmium absorption energy range. The MCNP computer code was used to evaluate this (see Appendix C). The results showed no significant downscattering.

After evaluating this data for the copper foil, a report (Eisen et al. 1985) which investigated the problem with using copper foils for dose determination was discovered. The authors examined four distinct energy ranges of neutrons that a cadmium covered copper foil would be exposed to in a criticality accident. These were: $E_{c}-15 \mathrm{keV}\left(\mathrm{E}_{\mathrm{c}}=\right.$ cadmium cut-off energy, $0.5 \mathrm{eV}), 15-200 \mathrm{keV}, 200 \mathrm{keV}-1 \mathrm{MeV}$ and $\mathrm{l}-15 \mathrm{MeV}$. The findings show that the major portion of the measured foil activity is due to neutrons in the $E_{c}-15 \mathrm{keV}$ energy range. The spectrum averaged cross section, however, is averaged over the entire neutron energy range. This will lower the value for the calculated cross section and thus increase the absorbed dose estimate. This is contrary to the fact that the majority of the dose received is due to neutrons in the $15 \mathrm{keV}$ to $15 \mathrm{MeV}$ energy range. The results of this study would indicate that with detailed information on the neutron spectrum it would be possible to correct for this phenomenon. This study also shows that an improperly defined spectrum, especially in the $E_{c}-15 \mathrm{keV}$ energy range, will add a significant error in the dose estimate.

\section{Dose calculation comparisons}

Fig. 9 compares reference doses with doses calculated with LANL supplied spectra and IAEA Publication 180 (IAEA 1978) spectra. The calculated doses were 


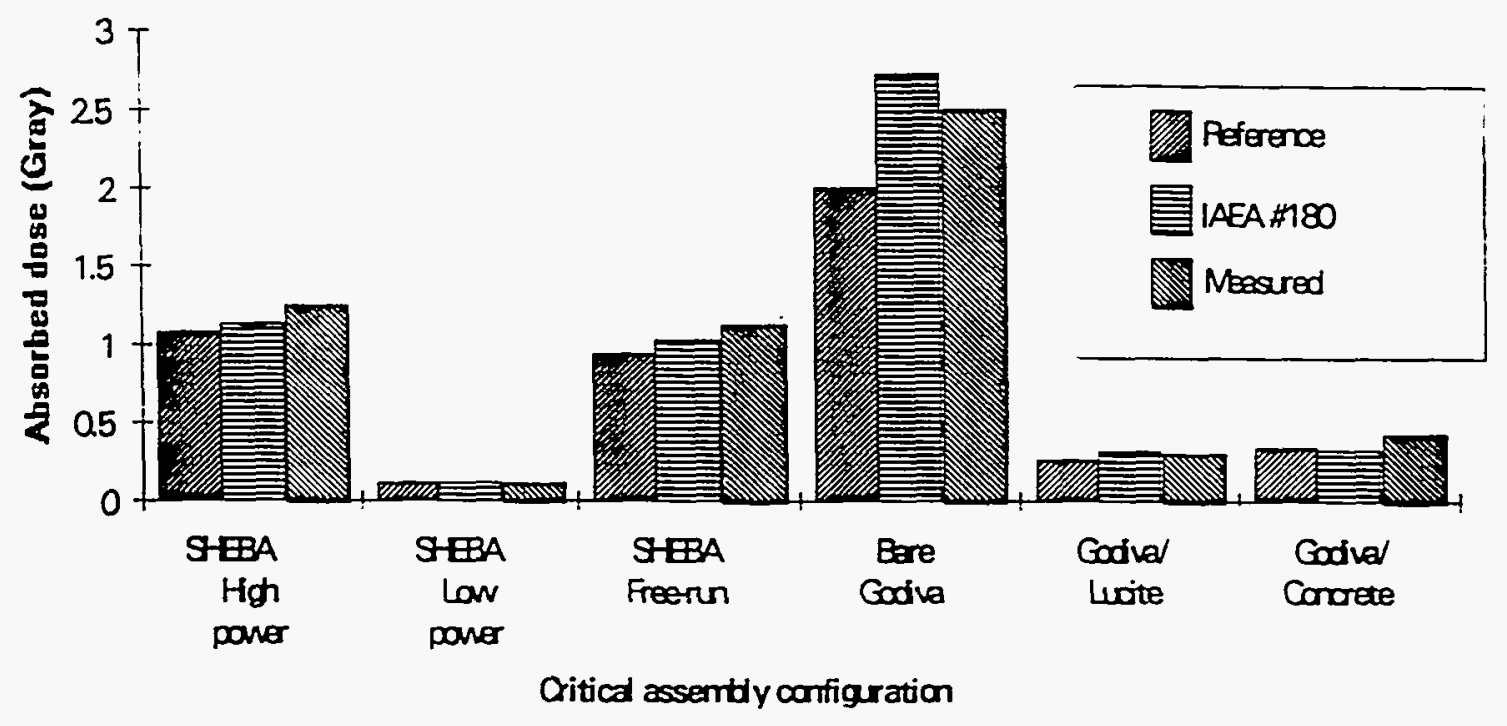

Fig. 9. Dose calculation comparisons. 
obtained by using the In foil data. In most cases, the values tabulated in IAEA Publication 180 (IAEA 1978) resulted in a slightly closer dose estimate.

\section{Activated sodium comparisons}

The results of the body orientation portion of this experiment are shown in Fig. 10. Several observations can be made from these results. The first is the significant difference between the spectral responses for both the AP and LAT orientations. The reason for this response is that up to $80 \%$ of thermal neutrons incident on the body diffuse back out of the body (Attix 1978). This effect is confirmed by comparing Fig. 11 with Fig. 4 . The large absorption cross section for the ${ }^{23} \mathrm{Na}(\mathrm{n}, \gamma)^{24} \mathrm{Na}$ reaction at low neutron energies and the number of low energy neutrons reflected from the phantom is evident by comparing the albedo effect for the two different materials.

The PA orientation does not exhibit this large difference in activities. Assuming a solid phantom made of paraffin, the mean free path of thermal neutrons through the phantom is approximately $17.4 \mathrm{~cm}\left(\sigma_{\mathrm{T}}=45\right.$ barns $)$. The mean free path of a $1.0 \mathrm{MeV}$ neutron ( $\sigma_{\mathrm{T}}=4.5$ barns) is approximately 10 times that distance. To state this another way, a thermal neutron has only a $42 \%$ probability of traveling through the $15 \mathrm{~cm}$ phantom without having a collision while the $1.0 \mathrm{MeV}$ neutron has a $92 \%$ probability. The mean free path for higher energy neutrons rapidly increase in the $\mathrm{MeV}$ energy range. Therefore, while the total neutron fluence is increased without the boron carbide in place, the lower energy neutrons are much more likely to undergo an elastic collision or 


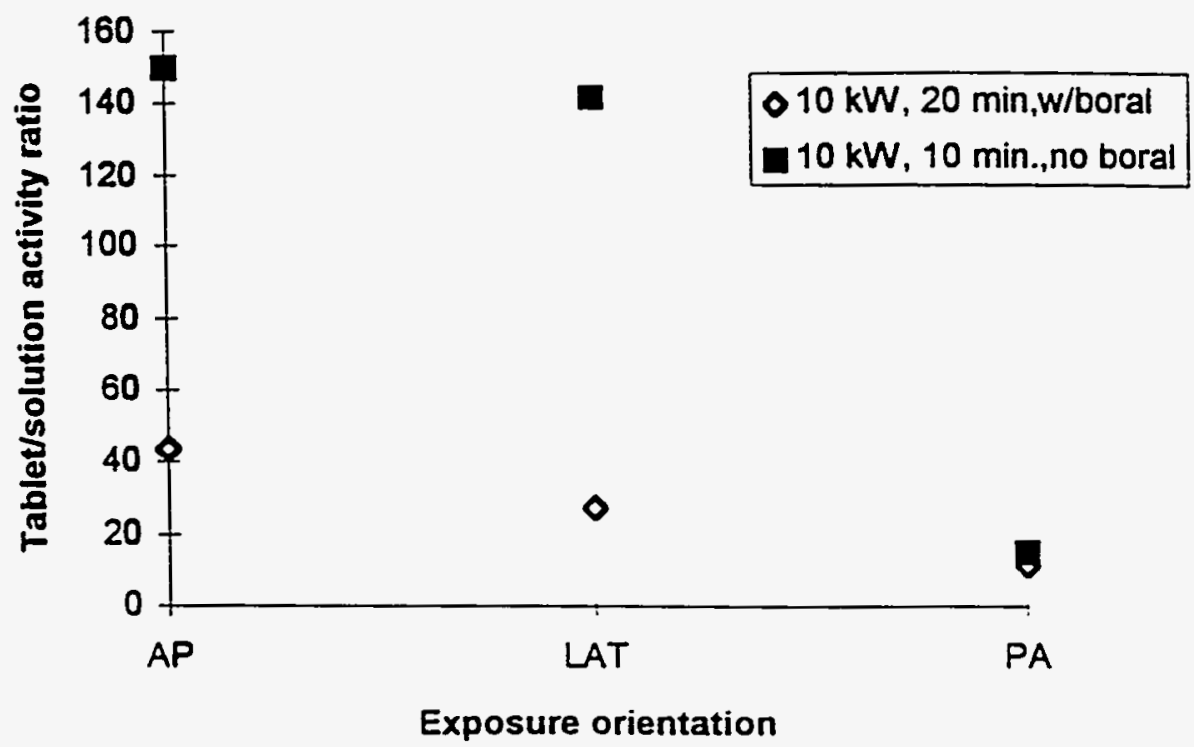

Fig. 10. Activated sodium ratios. The specific activity of the tablet is divided by the activity in $1 \mathrm{ml}$ of solution.

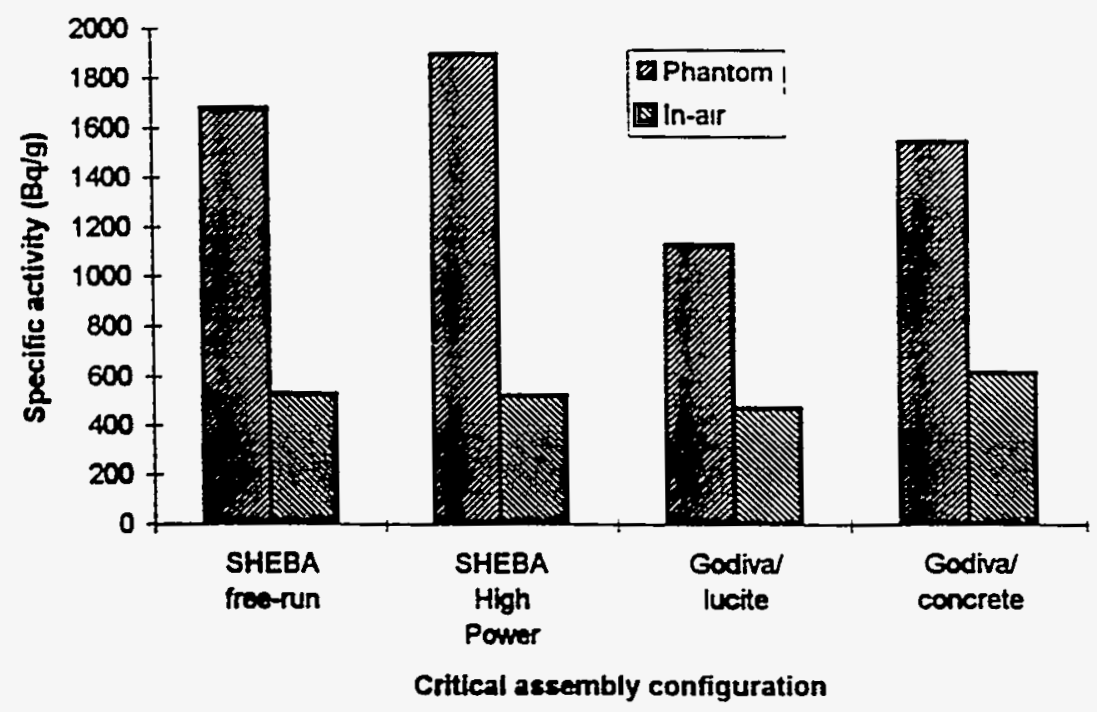

Fig. 11. Albedo effect on $\mathrm{NaF}$ tablets. 
absorption process within the phantom. Thus the majority of these neutrons will not be detected by the dosimeter measuring the PA exposure.

The second observation is the apparent consistency in the PA ratios. This would suggest that this ratio could be used to correct the estimate of absorbed dose. The importance of this is illustrated by the fact that In foils, which were irradiated in the same orientations, showed a factor of 6 difference between AP and PA activity. As the In foil activity is directly related to dose, this would suggest that the PA exposure will result in a dose estimate that is too low by a factor of 6 .

Lastly, inflated activity ratios, such as those for the AP and LAT orientations, can be used to indicate a large low energy neutron component in the incident spectrum. This could serve as a warning that the copper foil estimate is of little value for reasons previously cited. This would be especially significant if the other foils were not activated. In this instance, other methods would need to be evaluated to determine the dose such as blood or hair activation.

The foils for this portion of the experiment were generally counted at the $5 \%$ uncertainty level as were the sodium solutions. As this portion of the experiment was mostly qualitative in nature, errors such as placement of the reactor next to the irradiation cell, timing of the reactor before scram, and placement of the phantom in the irradiation cell were not considered for computational purposes. These parameters were taken into consideration during the performance of the experiment and every attempt was made to duplicate the settings for each irradiation. 
One may question the validity of the activity ratios due to the dilution factor of 1000 compared to reference man. In an attempt to answer this, I calculated the value $\mathrm{e}^{-\Sigma \mathrm{st}}$ where $\Sigma_{\mathrm{a}}$ is the macroscopic absorption cross section for the ${ }^{23} \mathrm{Na}(\mathrm{n}, \gamma)^{24} \mathrm{Na}$ reaction. For illustrative purposes I used the value of $\sigma_{2}$ as calculated by SNL-SAND-II for the Godiva spectrum through $20 \mathrm{~cm}$ concrete $(0.06962$ barns). The dilution factor of 1000 was included in the calculation of $\Sigma_{\mathrm{a}}\left(3.5 \mathrm{E}-09 \mathrm{~cm}^{-1}\right.$ vs. $3.5 \mathrm{E}-06 \mathrm{~cm}^{-1}$ for reference man). However, the diameter of the polyethylene bottle holding the sodium solution in the phantom is only $9 \mathrm{~cm}$. Therefore, the product $\Sigma_{\mathrm{a}} \mathrm{t}$ is sufficiently small that the value of $\mathrm{e}^{-\Sigma_{\mathrm{at}}}$ is approximately 1.0 for both sodium concentrations. Therefore, I conclude that the experimentally derived ratios here are valid. This is especially true in light of the fact that the same solution strength was used for all irradiations.

It should be noted, however, that a model that is more anthropomorphic in nature should be investigated. This would allow for such things as the normal mixing of blood in the body due to circulation which will have an effect on the sodium activity of the blood. 


\section{CONCLUSIONS}

The SNL PNAD is a reliable indicator of absorbed dose when the indium foil results are used. This is true for a variety of neutron spectra. All dose estimates were within the previous regulatory requirement of $\pm 30 \%$ of the reference dose. This is significant in that since there is now again a program in place to perform the intercomparisons, it is probable that this requirement will be reinstated in the future.

Except for copper, the other foils offer a valuable source of confirmation when they are activated. The reasons for the high dose estimates from the copper foil is well documented. In order to use this foil, future work will need to be directed towards deriving a modified response function for energies above $15 \mathrm{keV}$.

The results from the sodium activation portion of this experiment show that it is possible to distinguish between a PA exposure and an AP or LAT exposure. The results also show a difference by approximately a factor of 6 between the AP indicated dose and the PA indicated dose as measured by the In foil. Differentiating between AP and LAT exposure is not clearly defined when there are a significant number of low energy neutrons present. Future work in this area should be directed towards gathering data on orientations for a wider variety of neutron spectra. It is suggested that this portion be performed at the next intercomparison so that more realistic accident scenarios are studied. 


\section{REFERENCES}

Attix, F.H. Introduction to radiological physics and radiation dosimetry. New York: John Wiley \& Sons; 1978.

Coats, R.L.; Griffin, P.J.; Thompson, D.S. Nuclear accident dosimeter (NAD) location and performance analysis. Sandia National Laboratories: Albuquerque, NM; 1990.

Cummings, F.M.; Endres, G.W.R.; Schwartz, R.B. Neutron dosimeter performance and associated calibrations at nuclear power plants. U.S. Nuclear Regulatory Commission, NUREG/CR-2233. National Technical Information Service; Springfield, VA; 1982.

Eisen, Y.; Vasilik, D.G.; Brake, R.J. Evaluation of the ${ }^{63} \mathrm{Cu}$ activation foil for determining the neutron dose in the energy range of $1 \mathrm{eV}$ to $1 \mathrm{MeV}$. LA-10074-MS: Los Alamos National Laboratory: Los Alamos, NM; 1985.

Griffin, P.J.; Kelly, J.G.; Luera, T.F.; Vandenburg, J. SNL RML recommended dosimetry cross section compendium. SAND92-0094:Sandia National Laboratories: Albuquerque, NM; November, 1993.

International Atomic Energy Agency. Compendium of neutron spectra in criticality accident dosimetry. Vienna: International Atomic Energy Agency; Technical report series No. 180; 1978.

International Atomic Energy Agency. Dosimetry for criticality accidents. Vienna: International Atomic Energy Agency; Technical report series No. 211; 1982.

International Commission on Radiological Protection. Report of the task group on reference man. Oxford: Pergamon Press; ICRP Publication No. 23; 1974.

Leggett, R.W.; Williams, L.R. Regional blood volumes. Health Physics 60:139-154; 1991.

McElroy, W.N.; Berg, S.; Crockett, T.; Hawkins, R.G. A computer-automated iterative method for neutron flux spectra determination by foil activation. Vol. I, II, III and IV. AFWL-TR-67-41. Air Force Weapons Laboratory; September, 1967.

Patternoster, R.R.; Anderson, R.E.; Butterfield, J.B.; Cappielo, C.C.; Partin, B.Q.; Malenfant, R.E. Safety analysis report for Pajareto site (PA-8-18) and the Los Alamos Critical Experiments Facility (LACEF). LA-CP-92-235, Rev. 1.0. Los Alamos National Laboratory: Los Alamos, NM; June 1, 1994.

U.S. Department of Energy. Federal Register. Vol. 58, No. 238. Washington. DC; U.S Government Printing Office; December, 1993. 


\section{APPENDIX A}

\section{DIAGRAMS OF CRITICAL ASSEMBLIES}




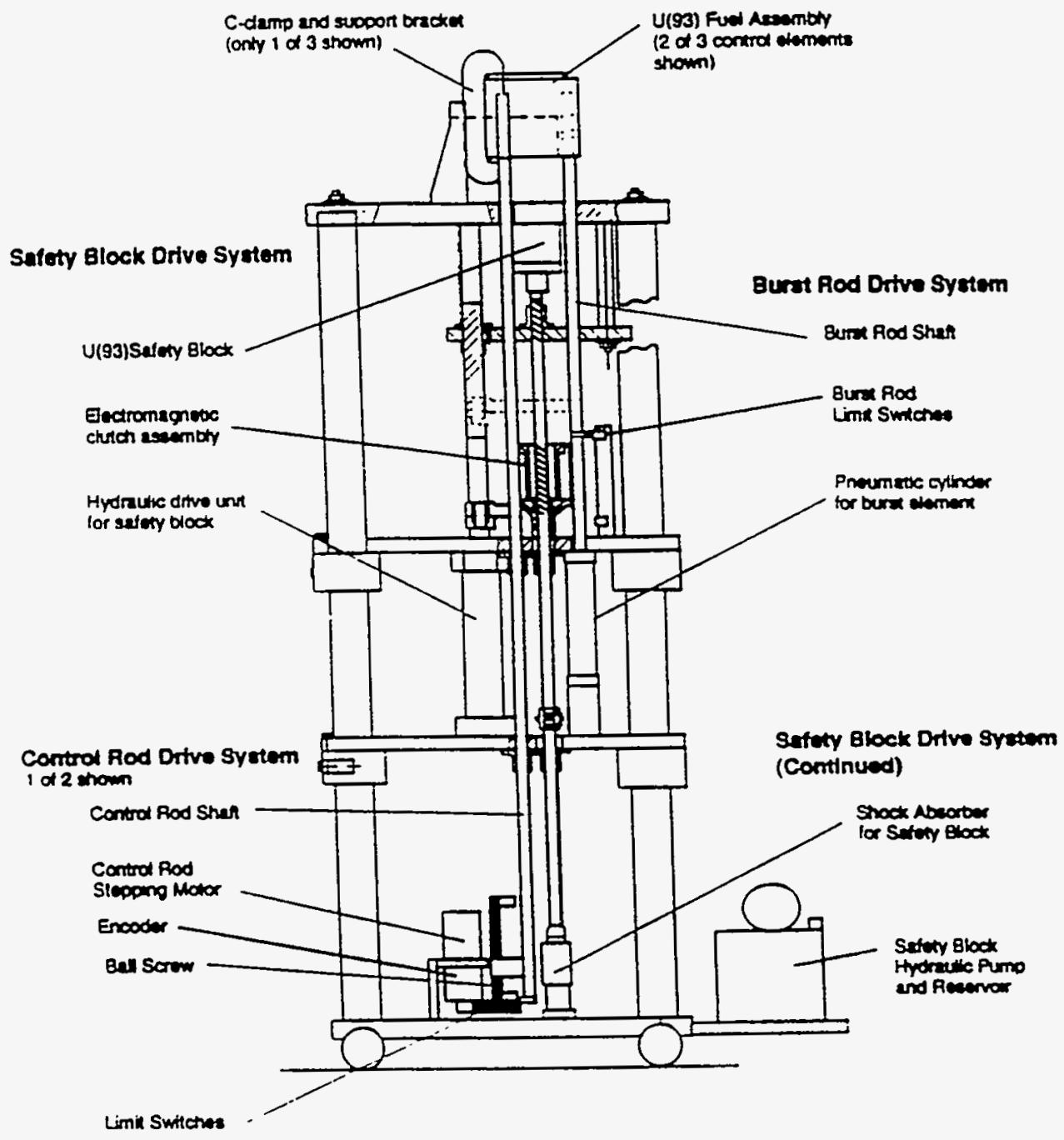

Fig. 12. The Godiva critical assembly. Reproduced from Patternoster et al. 


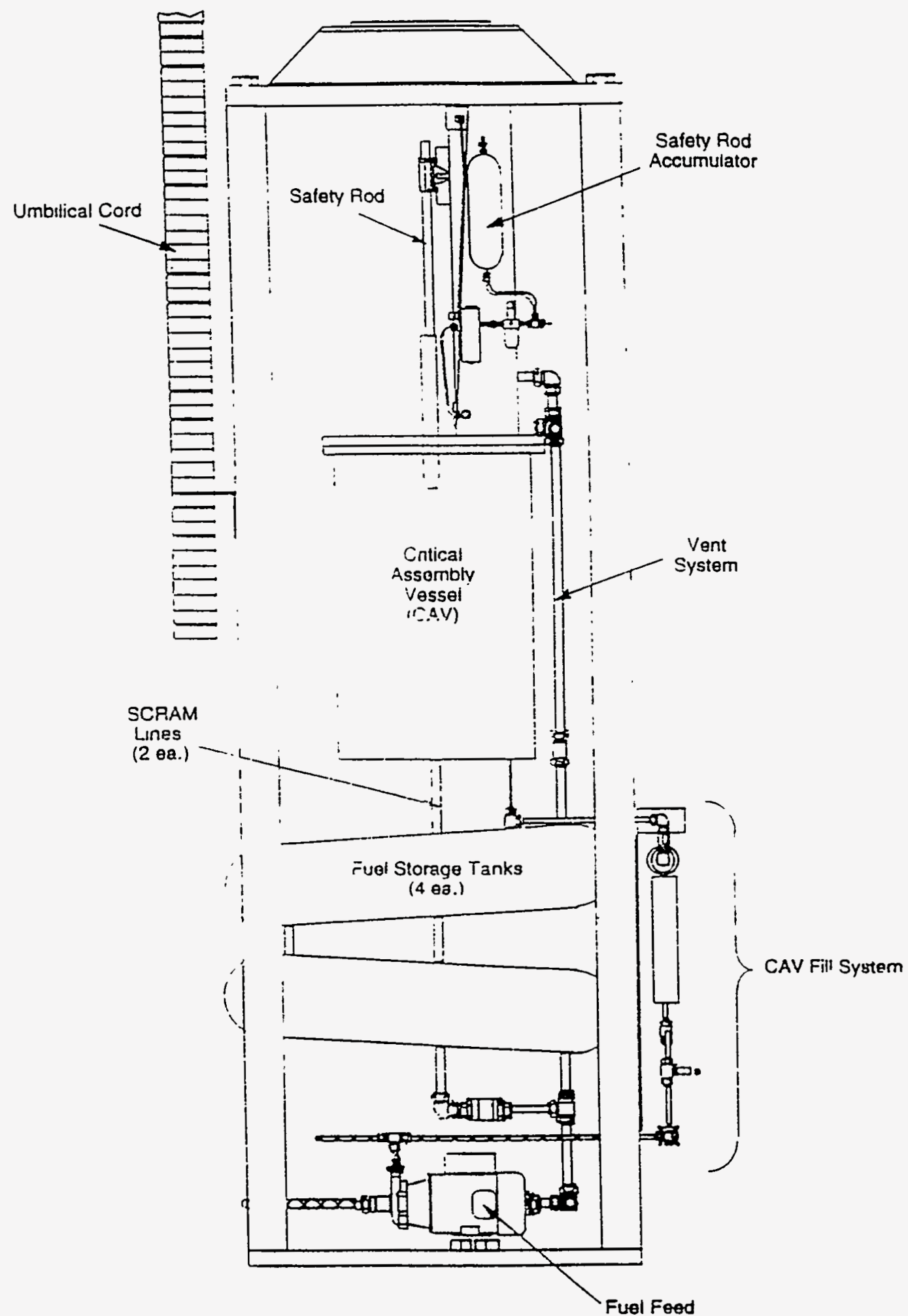

Fig. 13. The SHEBA critical assembly Pump Reproduced from Patternoster et al. 
APPENDIX B

NEUTRON SPECTRUM DATA 


\begin{tabular}{|c|c|c|c|c|c|}
\hline nergy & $\begin{array}{l}\text { SHEBA } \\
\text { Spectrum }\end{array}$ & Kerma & $\begin{array}{l}\text { Isarged } \\
\text { article }\end{array}$ & Igamma & se equiv \\
\hline 1.0E-08 & & & & & \\
\hline i $9 E-07$ & 3589.794 & 0 & 37 E.OS & 0 & $38 \mathrm{E} .08$ \\
\hline $2.5 E-07$ & 3695.272 & $3.5 E-10$ & $? 1 \mathrm{E}-09$ & 2.1E-08 & $44 E-08$ \\
\hline E.0E-07 & 4279.651 & $32 E-10$ & $34 \mathrm{E} \cdot 09$ & $2.3 E-08$ & $5.2 E-0.8$ \\
\hline $10 E-06$ & 3807.606 & $20 E \cdot 10$ & $2.9 E-03$ & 2.NE-08 & $+8 E-08$ \\
\hline $2.2 E-06$ & 3066.674 & ! $1 E-10$ & $23 E-09$ & I SE-08 & $38 E-08$ \\
\hline 4.7E-06 & 2310.274 & $58 E \cdot 11$ & 1.6E-09 & $\therefore .1 E-08$ & 2 9E- 08 \\
\hline 0.00001 & 1788.059 & $3.1 E \cdot 11$ & $1.2 E-09$ & $8.2 E-09$ & 2.2E.08 \\
\hline 0.000022 & 1481.62 & i $7 E-11$ & D SE-10 & 6.5E-09 & $1.8 \mathrm{E}-08$ \\
\hline 0.000047 & 1313.766 & $: .3 E \cdot ! 1$ & E $1 E \cdot 10$ & 5 5E-09 & $1.6 \mathrm{E}-08$ \\
\hline 0.0001 & $i 240.033$ & $12 E-i 1$ & $73 \mathrm{E}-10$ & ; 9E-09 & $15 E-08$ \\
\hline 0000215 & 1255.224 & $18 E-11$ & OE-10 & $+9 E .09$ & $14 E-08$ \\
\hline 0.000465 & 1363.258 & $.3 E-11$ & $73 E-10$ & 5.2E-09 & $15 E-0 E$ \\
\hline 0.001 & 1557.974 & : $1 E-10$ & $\triangle O E-10$ & $58 E-09$ & $: 6 \mathrm{E} \mathrm{OS}$ \\
\hline 0.00215 & 1857.338 & $.7 \mathrm{E} \cdot 10$ & $\therefore 1 E-10$ & j8E.09 & I $9 E-0 s$ \\
\hline 0.00465 & 2271.833 & 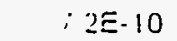 & i 1E-09 & $22 E .09$ & $23 E .08$ \\
\hline 001 & 2745.2 & . & , $8 E .09$ & $9.7 E .09$ & $2.7 E$ Us \\
\hline 00126 & 3225.529 & - $3 E .09$ & $\vdots 1 E-09$ & : 1 E.C8 & $35 E$ o8 \\
\hline 00158 & 3722.198 & - AE-CS & $\therefore 3 E-0 \hat{3}$ & $3 E=08$ & + BE SE \\
\hline 0.02 & 4145876 & $::-00$ & $=\overline{0 E-09}$ & $+E-09$ & $=4 E$ \\
\hline 00251 & $\therefore 506.775$ & HE.08 & ? & SE 08 & 马 $3 E$ \\
\hline 0316 & $\$ 811.115$ & : TE-08 & $\therefore$ JE.09 & $5 E \cdot 08$ & | 12.01 \\
\hline 00398 & 5090.754 & $\therefore J E-0 B$ & - 2E.08 & : 7E.08 & - 2E: \\
\hline 00501 & $\$ 437869$ & $\angle$ SE.OC & $5 E .08$ & - QE.08 & $17 E:$ \\
\hline 0.0631 & 587106 & $20 E .08$ & . JE-03 & - UE.08 & $\therefore 2 E-1^{3} !$ \\
\hline 0.0794 & 0456.566 & : $\because E-08$ & .. 5E.08 & $=2 E .08$ & Zytu: \\
\hline 0.1 & 7064.343 & $\therefore 7 E-08$ & 2 ?E-OB & $23 E .08$ & 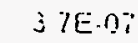 \\
\hline 0.126 & 7712.066 & $\because J E . C S$ & $\therefore 2 E .08$ & $=.5 E .09$ & ISE $0 \%$ \\
\hline 0.158 & 8553.504 & IE.08 & ธ5E.08 & 2.SE-08 & j \\
\hline 02 & 9486.169 & $22 E \cdot 08$ & 7 3E.08 & $=1 E .08$ & $35 E-0:$ \\
\hline 0251 & 10509.89 & : $2 E-0 ̂ 7$ & 는 $6 \mathrm{E}$ & $2+E-08$ & $11 E .60$ \\
\hline 0316 & 11569.33 & : HE.07 & ! 2E-07 & $37 \mathrm{E}-08$ & $15 E 06$ \\
\hline 0398 & $i 2324.03$ & I / $E .07$ & : OE 07 & $38 E-08$ & i gE \\
\hline 0.501 & 127271 & $\therefore U E-07$ & : 'JE-07 & $\leq 7 E .08$ & $23 E$ U० \\
\hline 0631 & 12912.86 & $\therefore 3 E \cdot G 7$ & $\therefore$ HE.07 & 3 SE 08 & $2 \mathrm{UE}$ \\
\hline 0.794 & 13382.89 & $\therefore 5 \mathrm{E}-07$ & \ 9E-07 & 2 HE-08 & $3+E$ บó \\
\hline 1 & 1398708 & . OE.07 & : $0 E .07$ & 3 3E-08 & $+2 E 06$ \\
\hline 126 & 1414126 & ; $4 E-07$ & : $1 E-07$ & $32 E-08$ & $+8 E .05$ \\
\hline 158 & 13879.05 & : $7 E-\cup 7$ & $45 E-0 \%$ & $2.9 E-08$ & $50 E-00$ \\
\hline 2 & 13632.42 & $+\mid E-07$ & $+8 E-07$ & 2.7E-08 & $52 E .06$ \\
\hline 2.51 & 13807.68 & $\because 6 E-07$ & 5 3E-07 & $2.6 E-08$ & 5.5E-06 \\
\hline 3.16 & 13884.16 & $=1 E-07$ & 5 9E-07 & $2.4 E-08$ & 5.6E-0G \\
\hline 3.98 & 12962.16 & 5 2E.07 & S OE-07 & $2.1 E-08$ & $52 E .06$ \\
\hline 5.01 & 10473.84 & $+6 E \cdot 07$ & $53 E-07$ & : $6 E-08$ & 4 3E.06 \\
\hline 6.31 & 7327.817 & $\because 6 E-07$ & \& $1 E-07$ & $11 E-08$ & 3 OE.06 \\
\hline 7.94 & 4688.81 & 2 SE-07 & 2.9E-07 & 8.1E-09 & $19 E-C 6$ \\
\hline 10.1 & 2736.916 & 1 GE-07 & $18 E-07$ & 7.3E-09 & $1.1 E-06$ \\
\hline 12.6 & 1463.348 & $03 E-08$ & i. IE.07 & 7 SE-09 & $60 \mathrm{OE}-07$ \\
\hline 15.8 & 711.0297 & 4 9E-08 & 5.7E-08 & 5 2E-09 & 3 CE-07 \\
\hline 20 & 298.2586 & $\therefore 3 E .08$ & 2 GE-08 & 2. 4 E.09 & 1 3E.07 \\
\hline 33 & 107.9807 & S $3 E .09$ & 1 1E.08 & $39 E \cdot 10$ & $47 E .08$ \\
\hline 59 & 28.59378 & 2.9E.09 & $36 \mathrm{E}-09$ & $2.4 E-10$ & : 3E-G8 \\
\hline 82.3 & 0 & 0 & 0 & 0 & 0 \\
\hline 160 & 0 & 0 & 0 & 0 & \\
\hline 223 & 0 & 0 & 0 & 0 & \\
\hline 435 & 0 & 0 & 0 & 0 & \\
\hline
\end{tabular}

Tulals $\quad 3.113 E+05 \quad 5888 E-00 \quad 6471 E-06 \quad 8$ 763E-07 $\quad 6.385 E .05$ 
Bare Godiva Kerma
Specirum

435.35838

43.744013

61.144912

46.565616

49.375083

60.564962

72.685439

85.765111

96.851467

104.90096

109.31903

110.30622

109.06665

106.18095

102.28026

80.259275

44.983804

29.346255

30.764703

33.138251

35.837471

39.727549

45.312265

52.343024

62.086257

75.869261

91.353737

111.84342

136.58532

158.35205

179.89194

207.90784

242.11528

277.38965

304.65999

326.22233

349.02984

366.40844

381.4036

375.18383

334.66068

275.52669

209.10423

138.49217

72.056642

28.922458

8.9616563

2.0957134

0.50459

0.0844566

\section{0}

$\begin{array}{r}1) \\ +2 E-12 \\ \hline\end{array}$

4.6E-12

$25 E-12$

$18 \mathrm{E}-12$

1.5E- 12

$12 E-12$

9.9E- 13

$9.7 E-13$

1 UE-12

I 6E-12

3 SE- 12

? AE-1?

1 GE- 11

3 LE- 11

ऽ $S E-11$

$38 E-11$

c) $7 E-11$

OIE-1i

IOE- 10

1 IE. 10

I รE. IU

2 IE.10

$27 E-10$

$3 / E-10$

\& EE. 10

7 JE 10

บ $6 E-10$

1 JE-09

1 /E-OS

2 2E-OS

$29 E-09$

I UE.OS

$+9 E-09$

¿ SE.OJ

7 IE.OS

उ $5 E-09$

9 SE-OS

1 1E-C8

1 2E-08

1 2E-08

I IE. 08

9 $3 E-09$

6 7E.09

3 8E.09

I 7E-09

5.7E-10

1. $5 \mathrm{E}-10$

3 BE- 11

7 BE- 12
Charged Pancle ngamma

$15 E-10$

$3.6 E-11$

4. $9 E-11$

3.6E- 11

3.6E-11

+. $3 E-11$

4. $9 E-11$

ร. 5 E-11

5.9E- 11

6.2E-11

ن. $1 E-11$

5. $9 E-11$

$56 E-11$

क $2 E-11$

$48 E-11$

: $3 E-11$

4. $3 E-11$

I IE- 11

+ $2 E-11$

5 4E- 11

(5) $9 E-11$

S $1 E-11$

I 2E-10

I $7 E-10$

$24 E-10$

j. SE-10

5 OE- 10

7 2E- 10

i OE.09

$14 E-09$

I $9 E-09$

$\therefore 7 E-09$

3 $7 E-09$

$\therefore$ OE-09

O 6 E-OG

3) 4 E-09

1 OE-08

1. $2 E-08$

$13 E-08$

$14 E-08$

$14 E-08$

$13 E-08$

1 1E-08

7.7E-09

4. 4 E-09

1.9E-09

6.6E-10

1.7E-10

4.5E-11

8.7E-12
0

2.5E-10

3. $4 E-10$

2.4E-10

2.5E-10

2.9E-10

3.3E-10

3.7E-10

4 OE- 10

$+2 \mathrm{E}-10$

$42 \mathrm{E}-10$

4. $2 \mathrm{E}-10$

4 1E-10

3 9E-10

3.7E-10

2. $8 \mathrm{E}-10$

$16 E-10$

: $0 E-10$

i IE-10

1 E- 10

1.2E-10

1 3E. 10

: $5 E \cdot 10$

1 BE- 10

2. E- 10

3.5E.10

3 OE. 10

3 7E- 10

$\div 5 E-10$

5.1E-10

E.7E-10

C) $4 E-10$

7 OE- 10

7 5E-10

$7.7 E-10$

7 BE-10

7 EE- 10

7 7E-10

7 SE-10

6 9E-10

5 8E-10

$+5 E-10$

3. $2 E-10$

2.1E-10

1.2E-10

7.8E-11

$+6 E-11$

I 5E-11

$+1 E-12$

7 OE-13

dose equiv

$$
\begin{aligned}
& 4.7 E \cdot 09 \\
& 5.2 E-10 \\
& 7.4 E-10 \\
& 5.8 E-10 \\
& 6.2 E-10 \\
& 7.5 E-10 \\
& 8.9 E-10 \\
& 1.0 E-09 \\
& 1.1 E-09 \\
& 1.2 E \cdot 09 \\
& 1.2 E-09 \\
& 12 E-09
\end{aligned}
$$

1 1E.US

1.1E.09

1 OE.OS

8 OE.! 0

4. $9 \mathrm{E} \cdot 1 \%$

3 8E- 10

$47 E-15$

6 IE-1U

$78 \mathrm{E}-10$

1 OE.US

$14 E .0 y$

I. 9E-US

2.8E-OY

$4.0 E .013$

5 BE.0Y

$84 E$ US

1.2E-0\%

$17 E-08$

2.3E.08

3.2E-0t

$+4 E-08$

6 OE-08

7.8E-08

9 8E.0\%

1. $2 \mathrm{E}-0 \%$

1 3E-07

1.5E-07

1.5E-07

1.3E-07

1.1E-07

8.5E-08

5.7E-0B

2.9E-OB

1.2E-08

3.7E-09

8.8E-10

2.1E-10

3.7E-1!

0
0
0
0
0

Totals

$6.703 E+03 \quad 1215 E-07 \quad 1.370 E-07 \quad 1.736 E-08 \quad 1.390 E-06$ 


\begin{tabular}{|c|c|c|c|c|c|}
\hline \multirow[t]{2}{*}{ nergy } & \multicolumn{2}{|c|}{$\begin{array}{l}\text { Godiva } \\
\text { Concrele (20 cmi) }\end{array}$} & \multirow[b]{2}{*}{ Cliarged } & \multirow{3}{*}{ ngamma } & \multirow{3}{*}{ lose $=q$} \\
\hline & Spectrum & Kerna & & & \\
\hline 1.0E-08 & & & & & \\
\hline 1.9E-07 & 1927.194 & 0 & 2.0E- 69 & 0 & 2.1E.08 \\
\hline 2.5E-07 & 94.45291 & $9.0 E-12$ & 7 OE-11 & $5.3 E-10$ & $1.1 E-C 9$ \\
\hline 5.0E-07 & 316.7188 & $2.4 E-11$ & $2.5 E-10$ & $1.7 E-09$ & $3.8 E-69$ \\
\hline $1.0 E-06$ & 315.0407 & $1.7 \mathrm{E}-11$ & $2.4 E-10$ & 1.7 E.09 & $3.9 E-09$ \\
\hline $2.2 E-06$ & 276.9979 & $10 E-11$ & $2.0 \mathrm{E}-10$ & 1.4E-09 & $3.5 E-0 \mathrm{~s}$ \\
\hline 4.7E-06 & 216.5857 & $5.4 \mathrm{E}-12$ & 1.5E-10 & $1.0 \mathrm{E} \cdot 09$ & 2.7E-Oy \\
\hline 0.00001 & 171.8304 & $2.9 E-12$ & $12 E-10$ & 7.9E-10 & 2.1E.09 \\
\hline 0.000022 & 151.0738 & $18 E-12$ & $97 E-11$ & $\Xi 6 E-10$ & $18 E-09$ \\
\hline 0.000047 & 148.3218 & $15 E-? 2$ & $9.1 \bar{z}-11$ & $0.2 E-10$ & $18 \mathrm{E} .09$ \\
\hline 0.0001 & 155.2649 & $1.6 E-12$ & $91 E-11$ & $6.2 E \cdot 10$ & 1.8E-09 \\
\hline 0.000215 & 159.9076 & $2.4 E-: 2$ & 9 UE-11 & $6.2 E-10$ & $18 E-09$ \\
\hline 0.000465 & 161.4383 & $\equiv 1 E-12$ & $\& 6 E-11$ & 6.tE-10 & $18 E-09$ \\
\hline 0.001 & 166.0702 & : IE-! I & $35 E-11$ & b. $2 E-10$ & $1.7 E: x^{2}$ \\
\hline 0.00215 & 174.7445 & $\therefore 6 E-1:$ & S $5 E-11$ & o $4 E-10$ & $18 E \cdot$. \\
\hline 0.00465 & 184.2504 & $58 E-1 !$ & \& $6 E-11$ & $6.6 \mathrm{E} \cdot 10$ & $19 E .09$ \\
\hline 0.01 & 162.9143 & $\mid 1 E-10$ & ! $1 E-10$ & $E-10$ & $16 \mathrm{E}-09$ \\
\hline 0.0126 & 102.5821 & $\angle O E-i$ & $: 9 E-1 i$ & $=-10$ & $11 E-09$ \\
\hline 00158 & 7031471 & 'SE.: & , IE-II & $2.4 E-10$ & ヨ1E・i \\
\hline 0.02 & 741798 & : $9 E-10$ & : & $26 E-10$ & i $1 E .0 S$ \\
\hline 0.0251 & 77.80477 & $\therefore 3 E-10$ & $3 E-10$ & $2.7 \mathrm{E} \cdot 10$ & $14 E .09$ \\
\hline 00316 & 8188341 & $\therefore$ QE. 10 & $6 E-10$ & $\therefore .8 E-10$ & $18 E .$. \\
\hline 0.0398 & 84.81914 & $\because$ IE-IO & $9 E-10$ & 2 9E-10 & $22 E=$ \\
\hline 0.0501 & 89.43679 & $\therefore 1 E-10$ & $=4 E-10$ & $=-10$ & 2 UE L \\
\hline 0.0631 & 97.7295 & $\therefore$ IE-!: & $=2 E-10$ & $=-10$ & $36 E-0,4$ \\
\hline 0.0794 & 99.04999 & $-B E-10$ & : $8 E-10$ & $3.3 E-10$ & I 4E.09 \\
\hline 0.1 & 1045 & $1 D E-10$ & $\therefore 8 E-10$ & $3.5 \mathrm{E}-10$ & 5 5E. 03 \\
\hline 0.126 & 118.7954 & $\because O E-10$ & S SE-10 & $E-10$ & 7 SE- \\
\hline 0.158 & i 29.7882 & IE.CG & $\approx 4 E-10$ & $43 E-10$ & $9.8 E 0$ \\
\hline 0.2 & 145.6909 & $: 4 E-09$ & .09 & $+7 E-10$ & $13 E \cdot 00$ \\
\hline 0.251 & 165.0126 & 18 E-09 & I SE-09 & -10 & $18 E-O$ \\
\hline 0.316 & 189.2272 & $23 E-09$ & $20 E-09$ & -10 & $2+E$ US \\
\hline 0.398 & 223.1088 & $\equiv$ IE.UY & $\because 9 E-09$ & j $9 E-10$ & 3 AE.C: \\
\hline 0.501 & 259.0425 & : OE.09 & \& UE.09 & 7 SE-10 & $47 E: 0$ \\
\hline 0631 & 296.5965 & $\therefore 2 E-09$ & $=4 E-09$ & 3 OE- 10 & $64 E-0 x$ \\
\hline 0.794 & 296.9303 & $=9 E-09$ & ० 4E.09 & $75 E-10$ & $75 E-\cup 6$ \\
\hline 1 & 263.7021 & $57 E .09$ & ن 8E.09 & $0.3 E \cdot 10$ & 7.9E-0b \\
\hline 1.26 & 243.2221 & $=9 E-09$ & ? IE-09 & $54 E-10$ & 3.2E-C3 \\
\hline 1.58 & 248.844 & ड 7E-09 & 20 & -10 & 9 OE-SE \\
\hline 2 & 265.2275 & 7 9E-09 & .09 & $=-10$ & $1.0 E-07$ \\
\hline 2.51 & 249.9561 & \& $3 E-09$ & $\because 6$ & -10 & $9.9 E-G 8$ \\
\hline 3.16 & 181.2917 & ij 6 E-09 & 77 & $=-10$ & T.3E-OU \\
\hline 3.98 & 113.5128 & $\because 6 E-09$ & & $=-10$ & $46 E-U C$ \\
\hline 5.01 & 76.85706 & $\therefore 4 E-09$ & 39 & io & $3.1 E 0$ \\
\hline 6.31 & 48.87796 & 2.4E-09 & 2.7 & 11 & E-08 \\
\hline 7.94 & 25.41665 & $1+E-09$ & 16 & -11 & E.08 \\
\hline 10.1 & 11.96329 & $70 E-10$ & $\triangle O E-10$ & $E-11$ & $4.9 E-09$ \\
\hline 12.6 & 5.752028 & $37 E \cdot 10$ & $42 \mathrm{E}-10$ & $E-11$ & $2.4 E-09$ \\
\hline 15.8 & 2.855166 & $20 \mathrm{E}-10$ & 2.3E-10 & $E-11$ & $12 \mathrm{E}-09$ \\
\hline 20 & 1.370984 & $10 E-10$ & $12 E-10$ & $1.1 E-11$ & $5.8 E-10$ \\
\hline 33 & 0.308935 & $2.7 E-11$ & $3.2 \mathrm{E}-11$ & $2.6 E-12$ & $13 E-10$ \\
\hline 59 & 0 & 0 & 0 & 0 & \\
\hline 82.3 & 0 & 0 & 0 & 0 & 0 \\
\hline 160 & 0 & 0 & 0 & 0 & 0 \\
\hline 223 & 0 & 0 & 0 & 0 & 0 \\
\hline 435 & 0 & 0 & 0 & 0 & \\
\hline ads & 28.457 & .0 & $4 E-08$ & $.5 E-08$ & JE.06 \\
\hline
\end{tabular}




\begin{tabular}{|c|c|c|c|c|c|}
\hline $\begin{array}{l}\text { nergy } \\
1.0 \mathrm{E}-08\end{array}$ & $\begin{array}{l}\text { Lucite, } 12 \mathrm{c} \\
\text { Spectrum }\end{array}$ & Kerma & liürged & ngamma & ose eq \\
\hline $1.9 \mathrm{E}-07$ & 3607.059 & 0 & 2.0E-09 & 0 & 2.1E-0s \\
\hline 2.5E-07 & 93.52334 & $9.0 E-: 2$ & $7.8 E-11$ & $5.3 E-10$ & 1.1E-OG \\
\hline 5.0E-07 & 275.4249 & $2.4 E-11$ & $2.5 E-10$ & 1.7E-09 & 3.8E-09 \\
\hline $1.0 \mathrm{E}-06$ & 211.8145 & $1.7 E-11$ & $2.4 E-10$ & $1.7 E-09$ & $3.9 E-09$ \\
\hline 2.2E-06 & 255.6004 & $10 E-11$ & $2.0 \mathrm{E}-10$ & 1.4E-09 & $3.5 E-09$ \\
\hline 4.7E-06 & 257.7931 & $5.4 E-12$ & $1.5 \mathrm{E} \cdot 10$ & $1.0 E-09$ & 2.7E-09 \\
\hline 0.00001 & 241.0866 & $2.9 E-12$ & $12 E-10$ & $7.9 E-10$ & 2.1E-09 \\
\hline 0.000022 & 224.8809 & $18 E \cdot 12$ & $S 7 E-11$ & 6.6E-10 & $1.8 \mathrm{E}-09$ \\
\hline 0.000047 & 210.5845 & $1.5 E-12$ & $9.1 E-11$ & $6.2 E-10$ & $1.8 E-09$ \\
\hline 0.0001 & 198.555 & $16 E-12$ & $9.1 E-11$ & $5.2 E-10$ & $1.8 \mathrm{E}-09$ \\
\hline 0.000215 & 185.6654 & $34 E-1 ?$ & 9 OE-11 & $0.2 E-10$ & $18 E-09$ \\
\hline 0.000465 & 176.6372 & S.IE.!: & :6E-11 & 5.1E-10 & $18 E-00$ \\
\hline 0.001 & 169.3247 & $11 \mathrm{E}-1 !$ & 8.5E-11 & $52 E-10$ & $17 \mathrm{E}-\mathrm{U}$ \\
\hline 0.00215 & 165.4781 & $2.6 E-1:$ & B $5 E-11$ & $j 4 E-: 0$ & $1.8 E-G S$ \\
\hline 0.00465 & 162.6552 & $58 E-11$ & ४ $6 E-11$ & $6.6 E-10$ & $1.9 E-09$ \\
\hline 0.01 & 161.2837 & I IE- 10 & ' $1 E-10$ & $5.7 E-10$ & $16 \mathrm{E}-\mathrm{GS}$ \\
\hline 0.0126 & 48.71952 & $20 E-10$ & $\because 9 E-11$ & $36 E-10$ & $1.1 E 00$ \\
\hline 0.0158 & 47.07873 & ! 6E-19 & : 15.11 & $2.4 \mathrm{E}-10$ & $\Xi 1 E-:$ \\
\hline 0.02 & 49.54927 & 1 9E- 10 & $1 O E-10$ & $2.5 E-10$ & 1 1E \\
\hline 0.0251 & 50.88838 & $23 E-10$ & i $3 E \cdot 10$ & $2.7 E-10$ & $14 E \%$ \\
\hline 0.0316 & 51.17076 & 2 $3 E:$ & $: \leqslant E-10$ & $28 E-10$ & $18 E \cdot 1 \mathrm{~V}$ \\
\hline 0.0398 & 53.43867 & $?+E-10$ & : yE-10 & $3.9 E-10$ & $2.2 E: \because$ \\
\hline 0.0501 & 55.63877 & $\therefore$ IE.10 & $\approx E-10$ & 3 OE- 10 & 2.8E-i: \\
\hline 0.0631 & 61.3731 & $\div 1 E-10$ & $32 \mathrm{E}-10$ & $33 E-10$ & $36 \mathrm{E} \cdot 0 \mathrm{~s}$ \\
\hline 0.0794 & 64.48129 & 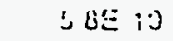 & i $\mathrm{u} E-10$ & $\therefore 3 E-10$ & $44 E-6:$ \\
\hline 0.1 & 70.74169 & $\because O E \cdot(1)$ & $.8 E-10$ & $35 E-10$ & 5 5E.0. \\
\hline 0.126 & 78.37416 & $\because 0 E \cdot 10$ & . دE-10 & $3.9 E-10$ & 7 5E-09 \\
\hline 0.158 & 83.48217 & $11=.09$ & $24 E-10$ & $43 E-10$ & $9.8 \mathrm{E} .09$ \\
\hline 0.2 & 96.60998 & ! AE.G9 & I IE-09 & $4.7 E-10$ & $13 E-08$ \\
\hline 0.251 & 106.7476 & I QE.09 & $15 E .09$ & $5.4 E-10$ & $18 E-08$ \\
\hline 0.316 & 124.8238 & $\because 3 E .09$ & ?.OE-09 & $5.0 E-10$ & $2.4 E-1.38$ \\
\hline 0.398 & 148.9946 & $\therefore 1 E .09$ & - JE-09 & o $9 E-10$ & $34 E-03$ \\
\hline 0.501 & 176.8855 & $\therefore 0 E-O S$ & $40 E-03$ & $75 E-10$ & $47 E-i s 3$ \\
\hline 0.631 & 212.2077 & $\Xi 2 E .(\mathrm{O})$ & S AE-09 & $3.0 E-10$ & E-28 \\
\hline 0.794 & 249.5073 & $\therefore B E-C Q$ & $54 E-09$ & $75 E-10$ & $76 E-08$ \\
\hline 1 & 299.3873 & $57 E C Q$ & j 8E-09 & $53 E-10$ & $79 E-i J 3$ \\
\hline 1.26 & 259.561 & 9E-09 د' & 7.1E-09 & -10 & $8.2 E \cdot 08$ \\
\hline 1.58 & 419.7183 & $0.7 E-09$ & -09 & 10 & $=-08$ \\
\hline 2 & 502.2394 & 7 YE.U & 3.3E-09 & $5.2 E-10$ & $1.0 E-07$ \\
\hline 2.51 & 457.0891 & 3 3E.09 & 3.6E-09 & $46 E-10$ & $9.9 E-08$ \\
\hline 3.16 & 428.9417 & 6.6E.C? & $\because 7 E-09$ & $3.1 E-10$ & 7.3E.08 \\
\hline 3.98 & 268.0073 & $46 E-C O$ & $\$ 3 E-09$ & $19 E-10$ & $46 E-08$ \\
\hline 5.01 & 138.1704 & 3.4E-C9 & 3.9E-09 & $1.2 \mathrm{E}-10$ & 3.1E-08 \\
\hline 6.31 & 109.3738 & 2.4E-C9 & 2.7 E-09 & $7.3 E-11$ & 2.0E-08 \\
\hline 7.94 & 54.9362 & 1.4E-09 & 1.6E-09 & $4.4 E-11$ & $1.0 E-08$ \\
\hline 10.1 & 14.74369 & $7.0 E-10$ & $6.0 \mathrm{E}-10$ & $3.2 E-11$ & 4.9E-09 \\
\hline 12.6 & 3.609427 & $37 \mathrm{E}-10$ & $+.2 E \cdot 10$ & $2.9 E-11$ & 2.4E-09 \\
\hline 15.8 & 0.963274 & $2.0 E-10$ & $2.3 E-10$ & $2.1 E-11$ & 1.2E.09 \\
\hline 20 & 0.000013 & $1.0 E-10$ & $1.2 E-10$ & $1.1 E-11$ & $5.8 E-10$ \\
\hline 33 & 0 & $2.7 \mathrm{E}-1 \mathrm{i}$ & $3.2 E-11$ & $2.6 E-12$ & $1.3 E-10$ \\
\hline 59 & 0 & 0 & 0 & 0 & \\
\hline 82.3 & 0 & 0 & 0 & 0 & 0 \\
\hline 160 & 0 & 0 & 0 & 0 & 0 \\
\hline 223 & 0 & 0 & 0 & 0 & 0 \\
\hline 435 & 0 & 0 & 0 & 0 & \\
\hline & 11485.82 & 8.4E-08 & $9.4 E-08$ & 2.5E-08 & $1.0 E-06$ \\
\hline
\end{tabular}


APPENDIX C

MCNP RESULTS OF FISSION NEUTRONS THROUGH A CADMIUM COVER 


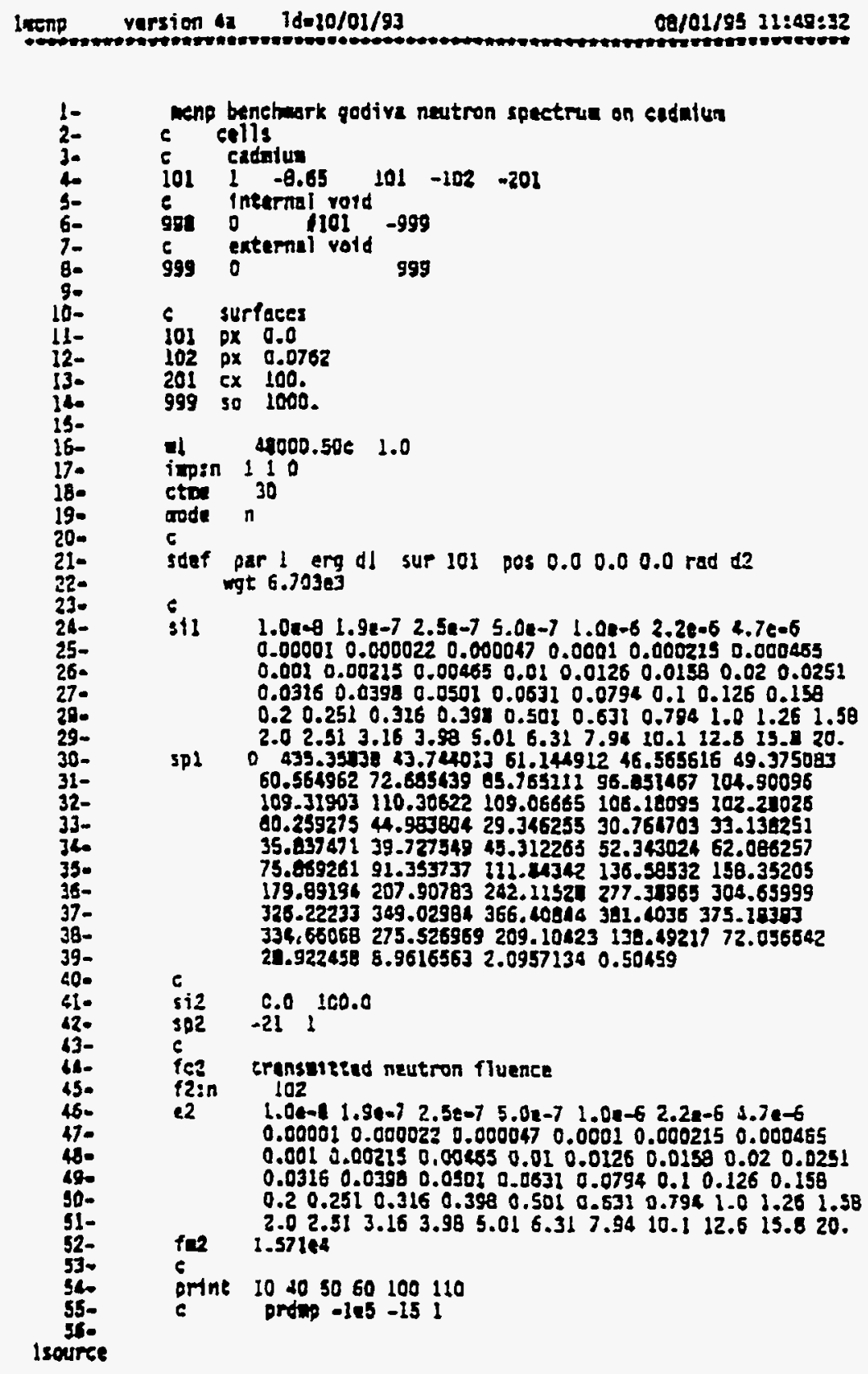


unbiased htstogran distribution

\begin{tabular}{|c|c|c|c|}
\hline $\begin{array}{l}\text { lource } \\
\text { enery }\end{array}$ & $\begin{array}{l}\text { souree } \\
\text { value }\end{array}$ & $\begin{array}{l}\text { cumilative } \\
\text { probubtlity }\end{array}$ & $\begin{array}{l}\text { probabllitey } \\
\text { of bin }\end{array}$ \\
\hline $\begin{array}{l}1 \\
2 \\
3 \\
4 \\
3 \\
6 \\
7 \\
8 \\
9 \\
10 \\
11 \\
12 \\
13 \\
14 \\
15 \\
16 \\
17 \\
18 \\
19 \\
20 \\
21 \\
22 \\
23 \\
26 \\
25 \\
28 \\
27 \\
28 \\
29 \\
30 \\
31 \\
32 \\
33 \\
34 \\
35 \\
36 \\
37 \\
38 \\
39 \\
40 \\
11 \\
42 \\
43 \\
46 \\
45 \\
49 \\
17 \\
46 \\
49 \\
30\end{array}$ & 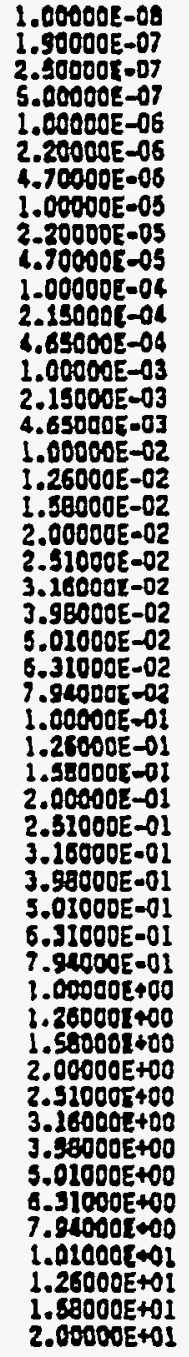 & 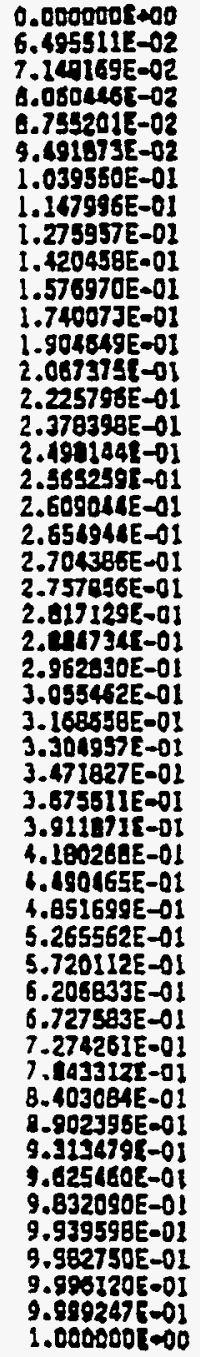 & 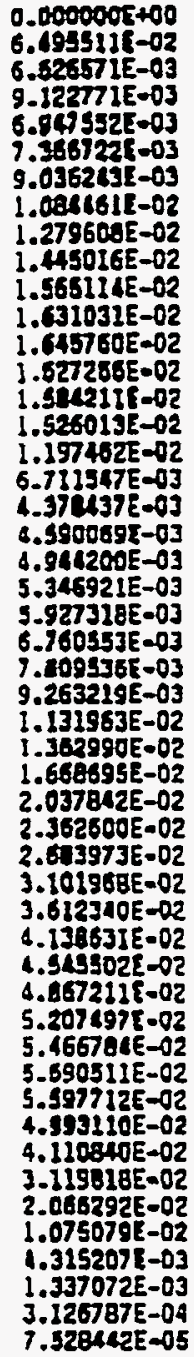 \\
\hline
\end{tabular}

arder of supling source variables. sup rad pos org twe

Interial composteton

material

maber cosponant nuelise, otom fraction

$140000,1.00000$ 
Pange of serolad source weights - $6.3030[003$ te $6.70308+03$ inewtion estirtey in exet call

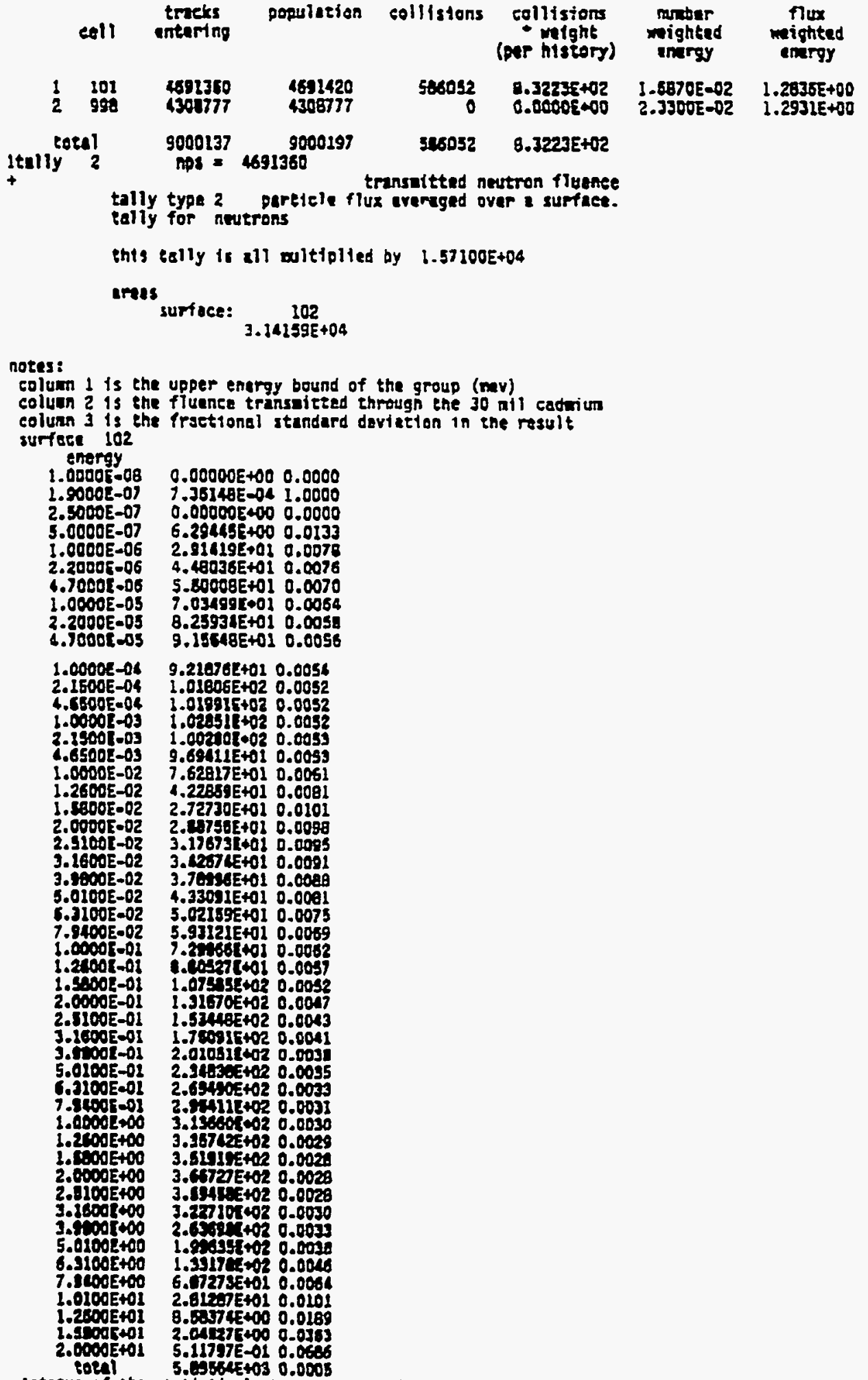

lstatus of the statistical shoeks used to Por confitemse infervals for the wan for sech tally bin 
Ronald Allen Burrows

\section{VITA}

Address: 9010 Petersham Dr., Houston, TX 77031

Education 1995 Department of Energy fellow, Master of Science in Health Physics, Texas A\&M University.

1991 Master of Business Administration, New Hampshire College.

1988 Bachelor of Science in Nuclear Engineering, University of New Mexico.

Experience MARE ISLAND NAVAL SHIPYARD, Mare Island, CA (Department of Defense)

April, 1992-

Oct., 1994 Mixed Waste (Radiological and Hazardous) Project Engineer

*Prevented a facility shutdown by identifying, purchasing, and implementing an alternative liquid waste processing system.

*Managed the shipyard mixed waste program.

*Assisted in the preparation of the shipyard Environmental Impact

Statement for yard closure.

\section{Emergency Planner}

*Streamlined emergency response procedures.

*Trained midlevel and upper management in emergency response actions.

July, 1988- PORTSMOUTH NAVAL SHIPYARD, Portsmouth, NH (Department of April, 1992 Defense)

\section{Radiological Control Engineer}

*Established, and completed ahead of schedule, a $\$ 500,000+$ innovative waste disposal project.

*Coordinated the manifesting of all shipyard radiological waste.

\section{Auditor}

*Enforced government and local regulations concerning contamination control and exposure reduction practices.

*Conducted audits of shipyard radiological work performance.

Professional Organizations

Member: American Nuclear Societ

Health Physics Society 